\title{
INFLATION TARGETS AND THE ZERO LOWER BOUND IN A BEHAVIORAL MACROECONOMIC MODEL
}

\author{
Paul De Grauwe \\ (London School of Economics) \\ Yuemei Ji \\ (University College London)
}

\begin{abstract}
We analyse the relation between the level of the inflation target and the zero lower bound (ZLB) imposed on the nominal interest rate in the framework of a behavioral New-Keynesian macroeconomic model in which agents, experiencing cognitive limitations, use adaptive learning forecasting rules. The model produces endogenous waves of optimism and pessimism (animal spirits) that lead to non-normal distributions of the output gap.

We find that when the inflation target is too close to zero, the economy can get gripped by "chronic pessimism" that leads to a dominance of negative output gaps and recessions, and in turn feeds back on expectations producing long waves of pessimism. Low inflation targets create the risk of persistence of recessions and low growth. In conclusion, our framework suggests that the $2 \%$ inflation target, now pursued by many central banks, is too low.
\end{abstract}

JEL: E03, E31, E32

Keywords: animal spirits, monetary policy, inflation target, behavioral economics, zero lower bound

*We are grateful to Francesco Caselli, Domenico Delli Gatti, Wouter den Haan, Doyne Farmer, Eddie Gerba, Daniel Gros, Cars Hommes, Ricardo Reis, Larry Summers and participants in seminars at the London School of Economics, CESifo (University of Munich), Jaume University, University College London and the University of Graz for helpful comments and suggestions. We also acknowledge the insightful comments of two anonymous referees that have helped to improve the quality of our paper. 


\section{Introduction}

Due to the presence of the zero lower bound (ZLB) on the nominal interest rate, an inflation target too close to zero risks pushing the economy into a negative inflation territory even when mild shocks occur. Economists have identified several risks associated with negative inflation. Two of these have received much attention in the economic literature. First, during periods of deflation the nominal interest rate is likely to hit the lower zero bound. When this happens the real interest rate cannot decline further. In fact when deflation intensifies, the real interest rate increases, further aggravating the deflationary dynamics. In such a scenario the central bank loses its capacity to stimulate the economy in a recession, thereby risking prolonged recessions (Eggertson and Woodford(2003), Aruoba, \& Schorfheide, F. (2013), Blanchard, et al. (2010), Ball(2014)).

Second, deflation raises the real value of debt leading to attempts of agents to reduce their debt by saving more. This adds to the deflationary dynamics. This debt deflation dynamics was first described by Fisher(1933) and has received renewed attention since the financial crisis of 2007-08 (see Koo(2011), Eggertsson and Krugman(2012)).

In this paper we focus on the first risk. Standard linear DSGE models have tended to underestimate the probability of hitting the ZLB as was shown by Chung, et al., (2012). Most of these models have led to the prediction that when the central bank keeps an inflation target of $2 \%$, it is very unlikely for the economy to be pushed into the ZLB (Reifschneider and Williams (1999), Coenen(2003), Schmitt-Grohe and Uribe(2007) ).

Building on a New Keynesian framework, we develop a behavioral macroeconomic model to shed new light on the nature of this risk. This model is characterized by the fact that agents experience cognitive limitations preventing them from having rational expectations. Instead they use simple forecasting rules (heuristics) and evaluate the forecasting performances of these rules expost. This evaluation leads them to switch to the rules that perform best. Thus, it 
can be said that agents use a trial-and-error learning mechanism. This is also called "adaptive learning".

This adaptive learning model produces endogenous waves of optimism and pessimism (animal spirits) that drive the business cycle in a self-fulfilling way, i.e. optimism (pessimism) leads to an increase (decline) in output, and the increase (decline) in output in term intensifies optimism (pessimism), see De Grauwe(2012), and De Grauwe and Ji(2016).

An important feature of this dynamics of animal spirits is that the movements of the output gap are characterized by periods of tranquility alternating in an unpredictable way with periods of intense movements of booms and busts. More technically, the dynamics of animal spirits leads to a non-normal distribution of the output gap with excess kurtosis and fat tails. This is a model that does not need large outside shocks to generate large movements in output.

We use this behavioral model to analyze how the level of the inflation target chosen by the central bank affects the dynamics created by animal spirits when a zero lower bound (ZLB) is imposed on the nominal interest rate. Our main results can be summarized as follows. First, we find that when the inflation target is too close to zero, the economy can get gripped by "chronic pessimism" that leads to a dominance of negative output gaps and recessions, and in turn feeds back on expectations producing long waves of pessimism. Using parameter calibrations that are generally found in the literature, our results suggests that an inflation target of $2 \%$, which has become the standard followed by central banks, is too low, i.e. it produces negative skewness in the distribution of the output gap. We find that an inflation target in the range of 3\% to $4 \%$ comes closer to producing a symmetric distribution of the output gap.

Second, when comparing the results obtained from our behavioral model with those obtained from the New Keynesian model under rational expectations (RE) we find that the behavioral model produces significantly more ZLB-hits than the RE-model. In addition when the interest rate is in the ZLB it remains stuck at zero much longer in the behavioral than in the RE-model. 
Third, we find that when the economy is pushed into a recession as a result of a negative demand shock, the high inflation target regime has better stabilizing properties. We find that in the high inflation target regime the persistence of the recession is shorter than in the low inflation target regime. That is, when the central bank sets a relatively high inflation target, the capacity of the system to lift itself out of the recession is stronger than when it sets a low inflation target. This is made possible by the stabilizing properties of monetary policies and by the ensuing elimination of self-fulfilling pessimism.

Fourth, an inflation target of $3 \%$ to $4 \%$ is more credible than an inflation target of $2 \%$. The reason is that in the latter case the economy finds itself more often in the ZLB than in the former. This reduces the central bank's capacity to control inflation and output gap.

The paper is organized as follows. Section 2 presents the model and its main characteristics. Sections 3 to 5 present the results of this model. Section 3 focuses on the features of the output gap and animal spirits and the frequency of hitting ZLB under different inflation target regimes. To understand the role of the animal spirits, we also compare the behavioral model with the rational expectations model. Section 4 discusses the impulse responses of the different endogenous variables to demand and supply shocks. Section 5 discusses credibility issues resulting from increasing the inflation target. Section 6 provides some empirical validation of the main predictions of the model. Section 7 contains the conclusion.

\section{The behavioral model}

\subsection{Model choice}

Mainstream macroeconomics has been based on two fundamental ideas. The first one is that macroeconomic models should be micro-founded, i.e. they should start from individual optimization and then aggregate these individuals' optimal plans to obtain a general equilibrium model. This procedure leads to aggregation problems that cannot easily be solved (Sonnenschein(1972), Kirman(1992)). One way to deal with the aggregation problems is to assume a representative 
agent, i.e. to assume that demand and supply decisions in the aggregate can be reduced to decisions made at the individual level.

The second idea is that expectations are rational, i.e. take all available information into account, including the information about the structure of the economic model and the distribution of the shocks hitting the economy.

We make a different choice of model. First, we will bring at center stage the heterogeneity of agents in that they have different beliefs about the state of the economy. As will be shown, it is the aggregation of these diverse beliefs that creates a dynamics of booms and busts in an endogenous way. The price we pay is that we do not micro-found the model and assume the existence of aggregate demand and supply equations. Second, we assume that agents have cognitive limitations preventing them from having rational expectations. Instead they will be assumed to follow simple rules of thumb (heuristics). Rationality will be introduced by assuming a willingness to learn from mistakes and therefore a willingness to switch between different heuristics. In making these choices we follow the road taken by an increasing number of macroeconomists, which have developed "agent-based models" and "behavioral macroeconomic models" (Tesfatsion, L. (2001), Colander, et al. (2008), Farmer and Foley(2009), Gatti, et

al.(2011), Westerhoff(2012), De Grauwe(2012), Hommes and Lustenhouwer(2016)).

\subsection{Basic model}

The model consists of an aggregate demand equation, an aggregate supply equation and a Taylor rule.

We assume the existence of an aggregate demand equation in the following way:

$$
y_{t}=a_{1} \widetilde{\mathrm{E}}_{\mathrm{t}} y_{t+1}+\left(1-a_{1}\right) y_{t-1}+a_{2}\left(r_{t}-\widetilde{\mathrm{E}}_{\mathrm{t}} \pi_{t+1}\right)+\varepsilon_{t}
$$

where $y_{t}$ is the output gap in period $\mathrm{t}, r_{t}$ is the nominal interest rate, $\pi_{t}$ is the rate of inflation, and $\varepsilon_{t}$ is a white noise disturbance term. The tilde above $E$ refers to the fact that expectations are not formed rationally. How exactly these expectations are formed will be specified subsequently. 
We follow the procedure introduced in New Keynesian DSGE-models of adding a lagged output in the demand equation. This can be justified by invoking inertia in decision-making. It takes time for agents to adjust to new signals because there is habit formation or because of institutional constraints. For example, contracts cannot be renegotiated instantaneously.

We assume an aggregate supply equation of the New Keynesian Philips curve type with a forward looking component, $\widetilde{\mathrm{E}}_{\mathrm{t}} \pi_{t+1}$, and a lagged inflation variable ${ }^{1}$ :

$$
\pi_{t}=b_{1} \widetilde{\mathrm{E}}_{\mathrm{t}} \pi_{t+1}+\left(1-b_{1}\right) \pi_{t-1}+b_{2} y_{t}+\eta_{t}
$$

Finally the Taylor rule describes the behavior of the central bank

$$
r_{t}=k_{3}\left[\pi^{*}+k_{1}\left(\pi_{t}-\pi^{*}\right)+k_{2} y_{t}\right]+\left(1-k_{3}\right) r_{t-1}+u_{t}
$$

where $\pi^{*}$ is the inflation target; The central bank is assumed to smooth the interest rate. This smoothing behavior is represented by adding a fraction of the lagged interest rate $r_{t-1}$ in equation (3). For simplicity we assume that the longterm equilibrium interest rate is zero and thus it does not appear in equation (3).

\subsection{Normalizing the model}

In order to solve the behavioral model following De Grauwe(2012), we first normalize the model. The inflation rates and interest rates can be expressed as deviations from the inflation target $\pi^{*}$. To be specific, we define these deviations as: $\pi_{t}^{\prime}=\pi_{t}-\pi^{*}, r_{t}^{\prime}=r_{t}-\pi^{*}$ and $r_{t-1}^{\prime}=r_{t-1}-\pi^{*}$, and $E_{t} \pi_{t+1}^{\prime}=E_{t} \pi_{t+1}-\pi^{*}$.

Equations (1)-(3) can be normalized as follows:

$$
\begin{aligned}
& y_{t}=a_{1} \widetilde{\mathrm{E}}_{\mathrm{t}} y_{t+1}+\left(1-a_{1}\right) y_{t-1}+a_{2}\left(r_{t}^{\prime}-\widetilde{\mathrm{E}}_{\mathrm{t}} \pi_{t+1}^{\prime}\right)+\varepsilon_{t} \\
& \pi_{t}^{\prime}=b_{1} \widetilde{\mathrm{E}}_{\mathrm{t}} \pi_{t+1}^{\prime}+\left(1-b_{1}\right) \pi_{t-1}^{\prime}+b_{2} y_{t}+\eta_{t} \\
& r_{t}^{\prime}=c_{1} \pi_{t}^{\prime}+c_{2} y_{t}+c_{3} r_{t-1}^{\prime}+u_{t}
\end{aligned}
$$

where $c_{1}=k_{1} k_{3}, c_{2}=k_{2} k_{3}, c_{3}=1-k_{3}$. 


\subsection{Introducing heuristics in forecasting output}

Agents are assumed to use simple rules (heuristics) to forecast the future output $\widetilde{\mathrm{E}}_{\mathrm{t}} y_{t+1}$. The way we proceed is as follows. We assume two types of forecasting rules. A first rule is called a "fundamentalist" one. Agents estimate the steady state value of the output gap (which is normalized at 0 ) and use this to forecast the future output gap ${ }^{2}$. A second forecasting rule is an "extrapolative" one. This is a rule that does not presuppose that agents know the steady state output gap. They are agnostic about it. Instead, they extrapolate the previous observed output gap into the future. The two rules are specified as follows:

The fundamentalist rule is defined by $\widetilde{\mathrm{E}}_{\mathrm{t}}^{\mathrm{f}} \mathrm{y}_{\mathrm{t}+1}=0$

The extrapolative rule is defined by $\widetilde{\mathrm{E}}_{\mathrm{t}}^{\mathrm{e}} \mathrm{y}_{\mathrm{t}+1}=y_{t-1}$

This kind of simple heuristic has often been used in the behavioral finance literature where agents are assumed to use fundamentalist and chartist rules (see Brock and Hommes(1997), Branch and Evans(2006), De Grauwe and Grimaldi(2006)). It is probably the simplest possible assumption one can make about how agents who experience cognitive limitations, use rules that embody limited knowledge to guide their behavior ${ }^{3}$. They only require agents to use information they understand, and do not require them to understand the whole picture.

Thus the specification of the heuristics in (4) and (5) should not be interpreted as a realistic representation of how agents forecast. Rather is it a parsimonious representation of a world where agents do not know the "Truth" (i.e. the underlying model). The use of simple rules does not mean that the agents are irrational and that they do not want to learn from their errors. We will specify a learning mechanism later in this section in which these agents continuously try to correct for their errors by switching from one rule to the other.

We assume that the market forecast can be obtained as a weighted average of these two forecasts, i.e.

$$
\widetilde{\mathrm{E}}_{\mathrm{t}} y_{t+1}=\alpha_{f, t} \widetilde{\mathrm{E}}_{\mathrm{t}}^{\mathrm{f}} \mathrm{y}_{\mathrm{t}+1}+\alpha_{e, t} \widetilde{\mathrm{E}}_{\mathrm{t}}^{\mathrm{e}} \mathrm{y}_{\mathrm{t}+1}
$$




$$
\begin{aligned}
& \widetilde{\mathrm{E}}_{\mathrm{t}} y_{t+1}=\alpha_{f, t} 0+\alpha_{e, t} \mathrm{y}_{\mathrm{t}-1} \\
& \text { and } \quad \alpha_{f, t}+\alpha_{e, t}=1
\end{aligned}
$$

where $\alpha_{f, t}$ and $\alpha_{e, t}$ are the probabilities that agents use a fundamentalist, respectively, an extrapolative rule.

In order to obtain some intuition about the mechanics arising from the use of these two rules it is useful to substitute (7) into equation (1a). Using (8) this yields

$$
y_{t}=\left(1-a_{1} \alpha_{f, t}\right) y_{t-1}+a_{2}\left(r_{t}^{\prime}-\widetilde{\mathrm{E}}_{\mathrm{t}} \pi_{t+1}^{\prime}\right)+\varepsilon_{t}
$$

It can be seen that when $\alpha_{f, t}=1$, i.e. the probability of all agents using the fundamentalist rule is equal to 1 , the coefficient in front of $y_{t-1}$ is $1-a_{1}$, while if $\alpha_{f, t}=0$, the probability of all agents using the extrapolative rule is equal to 1 , that coefficient is 1 . This makes clear that the source of the persistence in the output gap will be coming from the use of the extrapolative rule.

The forecasting rules (heuristics) introduced here are not derived at the micro level and then aggregated. Instead, they are imposed ex post, on the demand and supply equations. This has also been the approach in the learning literature pioneered by Evans and Honkapohja(2001). Ideally one would like to derive the heuristics from the micro-level in an environment in which agents experience cognitive problems. Our knowledge about how to model this behavior at the micro level and how to aggregate it is too sketchy, however. Psychologists and brain scientists struggle to understand how our brain processes information. There is as yet no generally accepted model we could use to model the microfoundations of information processing in a world in which agents experience cognitive limitations. We have not tried to do so ${ }^{4}$.

\subsection{Selecting the forecasting rules in forecasting output}

As indicated earlier, agents in our model are willing to learn, i.e. they continuously evaluate their forecast performance. This willingness to learn and to change one's behavior is a very fundamental definition of rational behavior. Thus our agents in the model are rational, not in the sense of having rational 
expectations. Instead our agents are rational in the sense that they learn from their mistakes. The concept of "bounded rationality" is often used to characterize this behavior.

The first step in the analysis then consists in defining a criterion of success. This will be the forecast performance (utility) of a particular rule. We define the utility of using the fundamentalist and extrapolative rules as follows:

$$
\begin{aligned}
& U_{f, t}=-\sum_{\mathrm{k}=0}^{\infty} \omega_{\mathrm{k}}\left[\mathrm{y}_{\mathrm{t}-\mathrm{k}-1}-\widetilde{\mathrm{E}}_{\mathrm{f}, \mathrm{t}-\mathrm{k}-2} \mathrm{y}_{\mathrm{t}-\mathrm{k}-1}\right]^{2} \\
& U_{e, t}=-\sum_{\mathrm{k}=0}^{\infty} \omega_{\mathrm{k}}\left[\mathrm{y}_{\mathrm{t}-\mathrm{k}-1}-\widetilde{\mathrm{E}}_{\mathrm{e}, \mathrm{t}-\mathrm{k}-2} \mathrm{y}_{\mathrm{t}-\mathrm{k}-1}\right]^{2}
\end{aligned}
$$

where $U_{f, t}$ and $U_{e, t}$ are the utilities of the fundamentalist and extrapolating rules, respectively. These are defined as the negative of the mean squared forecasting errors (MSFEs) of the forecasting rules; $\omega_{k}$ are geometrically declining weights. We make these weights declining because we assume that agents tend to forget. Put differently, they give a lower weight to errors made far in the past as compared to errors made recently. The degree of forgetting turns out to play a major role in our model. This was analyzed in De Grauwe(2012).

The next step consists in evaluating these utilities. We apply discrete choice theory (see Anderson, de Palma, and Thisse, (1992) and Brock \& Hommes(1997)) in specifying the procedure agents follow in this evaluation process. If agents were purely rational they would just compare $U_{f, t}$ and $U_{e, t}$ in (9) and (10) and choose the rule that produces the highest value. Thus under pure rationality, agents would choose the fundamentalist rule if $U_{f, t}>U_{e, t}$, and vice versa. However, psychologists have stressed that when we have to choose among alternatives we are also influenced by our state of mind (see Kahneman(2002)). The latter is to a large extent unpredictable. It can be influenced by many things, the weather, recent emotional experiences, etc. One way to formalize this is that the utilities of the two alternatives have a deterministic component (these are $U_{f, t}$ and $U_{e, t}$ in (9) and (10)) and a random component $\varepsilon_{f, t}$ and $\varepsilon_{e, t}$ The probability of choosing the fundamentalist rule is then given by

$$
\alpha_{f, t}=P\left[\left(U_{f, t}+\varepsilon_{f, t}\right)>\left(U_{e, t}+\varepsilon_{e, t}\right)\right]
$$


In words, this means that the probability of selecting the fundamentalist rule is equal to the probability that the stochastic utility associated with using the fundamentalist rule exceeds the stochastic utility of using an extrapolative rule. In order to derive a more precise expression one has to specify the distribution of the random variables $\varepsilon_{f, t}$ and $\varepsilon_{e, t}$. It is customary in the discrete choice literature to assume that these random variables are logistically distributed (see Anderson, Palma, and Thisse(1992), p.35). One then obtains the following expressions for the probability of choosing the fundamentalist rule:

$$
\alpha_{f, t}=\frac{\exp \left(\gamma U_{f, t}\right)}{\exp \left(\gamma U_{f, t}\right)+\exp \left(\gamma U_{e, t}\right)}
$$

Similarly the probability that an agent will use the extrapolative forecasting rule is given by:

$$
\alpha_{e, t}=\frac{\exp \left(\gamma U_{e, t}\right)}{\exp \left(\gamma U_{f, t}\right)+\exp \left(\gamma U_{e, t}\right)}=1-\alpha_{f, t}
$$

Equation (12) says that as the past forecast performance (utility) of the fundamentalist rule improves relative to that of the extrapolative rule, agents are more likely to select the fundamentalist rule for their forecasts of the output gap. Equation (13) has a similar interpretation. The parameter $\gamma$ measures the "intensity of choice". It is related to the variance of the random components. Defining $\varepsilon_{t}=\varepsilon_{f, t}-\varepsilon_{e, t}$. we can write (see Anderson, Palma and Thisse(1992)):

$$
\gamma=\frac{1}{\sqrt{\operatorname{var}\left(\varepsilon_{t}\right)}}
$$

When $\operatorname{var}\left(\varepsilon_{t}\right)$ goes to infinity, $\gamma$ approaches 0 . In that case agents decide to be fundamentalist or extrapolator by tossing a coin and the probability to be fundamentalist (or extrapolator) is exactly 0.5 . When $\gamma=\infty$ the variance of the random components is zero (utility is then fully deterministic) and the probability of using a fundamentalist rule is either 1 or 0 . The parameter $\gamma$ can also be interpreted as expressing a willingness to learn from past performance. When $\gamma=0$ this willingness is zero; it increases with the size of $\gamma$.

As argued earlier, the selection mechanism used should be interpreted as a learning mechanism based on "trial and error". When observing that the rule they use performs less well than the alternative rule, agents are willing to switch 
to the more performing rule. Put differently, agents avoid making systematic mistakes by constantly being willing to learn from past mistakes and to change their behavior. This also ensures that the market forecasts are unbiased.

\subsection{Heuristics and selection mechanism in forecasting inflation}

Agents also have to forecast inflation $\widetilde{E}_{t} \pi_{t+1}$. A similar simple heuristics is used as in the case of output gap forecasting, with one rule that could be called a fundamentalist rule and the other an extrapolative rule. (See Brazier et al. (2008) for a similar setup). We assume an institutional set-up in which the central bank announces an explicit inflation target. The fundamentalist rule then is based on this announced inflation target, i.e. agents using this rule have confidence in the credibility of this rule and use it to forecast inflation. Agents who do not trust the announced inflation target use the extrapolative rule, which consists in extrapolating inflation from the past into the future.

The fundamentalist rule will be called an "inflation targeting" rule. It consists in using the central bank's inflation target to forecast future inflation, i.e.

$$
\widetilde{\mathrm{E}}_{t}^{\mathrm{tar}} \pi_{t+1}=\pi^{*}
$$

or after normalization $\widetilde{\mathrm{E}}_{t}^{t a r} \pi_{t+1}^{\prime}=0$

where the inflation target is $\pi^{*}$

The "extrapolators" are defined by

$$
\widetilde{\mathrm{E}}_{t}^{e x t} \pi_{t+1}=\pi_{t-1}
$$

or after normalization $\widetilde{\mathrm{E}}_{t}^{e x t} \pi_{t+1}^{\prime}=\pi_{t-1}-\pi^{*}$

The market forecast is a weighted average of these two forecasts, i.e.

$$
\begin{array}{ll} 
& \widetilde{\mathrm{E}}_{t} \pi_{t+1}^{\prime}=\beta_{\text {tar }, t} \widetilde{\mathrm{E}}_{t}^{\text {tar }} \pi_{t+1}^{\prime}+\beta_{\text {ext }, t} \widetilde{\mathrm{E}}_{t}^{\text {ext }} \pi_{t+1}^{\prime} \\
\text { or } & \widetilde{\mathrm{E}}_{t} \pi_{t+1}^{\prime}=\beta_{\text {tar }, t} 0+\beta_{\text {ext }, t}\left(\pi_{t-1}-\pi^{*}\right)=\beta_{\text {ext }, t} \pi_{t-1}^{\prime} \\
\text { and } & \beta_{\text {tar }, t}+\beta_{\text {ext }, t}=1
\end{array}
$$


The same selection mechanism is used as in the case of output forecasting to determine the probabilities of agents trusting the inflation target and those who do not trust it and revert to extrapolation of past inflation, i.e.

$$
\begin{aligned}
& \beta_{t a r, t}=\frac{\exp \left(\gamma U_{t a r, t}\right)}{\exp \left(\gamma U_{t a r, t}\right)+\exp \left(\gamma U_{e x t, t}\right)} \\
& \beta_{\text {ext }, t}=\frac{\exp \left(\gamma U_{\text {ext, }, t}\right)}{\exp \left(\gamma U_{t a r, t}\right)+\exp \left(\gamma U_{e x t, t}\right)}
\end{aligned}
$$

where $U_{t a r, t}$ and $U_{\text {ext, } t}$ are the forecast performances (utilities) associated with the use of the fundamentalist and extrapolative rules in equation (21) and (22). These are defined in the same way as in (9) and (10), i.e. they are the negatives of the weighted averages of past squared forecast errors of using fundamentalist (inflation targeting) and extrapolative rules, respectively.

$$
\begin{aligned}
& U_{\text {tar }, t}=-\sum_{\mathrm{k}=0}^{\infty} \omega_{\mathrm{k}}\left[\pi_{\mathrm{t}-\mathrm{k}-1}-\widetilde{\mathrm{E}}_{\mathrm{f}, \mathrm{t}-\mathrm{k}-2} \pi_{\mathrm{t}-\mathrm{k}-1}\right]^{2} \\
& U_{\text {ext }, t}=-\sum_{\mathrm{k}=0}^{\infty} \omega_{\mathrm{k}}\left[\pi_{\mathrm{t}-\mathrm{k}-1}-\widetilde{\mathrm{E}}_{\mathrm{e}, \mathrm{t}-\mathrm{k}-2} \pi_{\mathrm{t}-\mathrm{k}-1}\right]^{2}
\end{aligned}
$$

This inflation forecasting heuristics can be interpreted as a procedure of agents to find out how credible the central bank's inflation targeting is. If this is very credible, using the announced inflation target will produce good forecasts and as a result, the probability that agents will rely on the inflation target will be high. If on the other hand the inflation target does not produce good forecasts (compared to a simple extrapolation rule) the probability that agents will use it will be small.

Finally it should be mentioned that the two prediction rules for the output gap and inflation are made independently. This is a strong assumption. What we model is the use of different forecasting rules. The selection criterion is exclusively based on the forecasting performances of these rules. Agents in our model do not have a psychological predisposition to become fundamentalists or extrapolators. However, it is possible that despite the assumption of independence, the realized choices generated from our model are actually correlated due to the interactions of the different variables in the model. We will come back to this when we implement the model and we will compute the 
realized correlation between the probabilities of being a fundamentalist for the output gap and a fundamentalist for inflation.

\subsection{Defining animal spirits}

The forecasts made by extrapolators and fundamentalists play an important role in the model. In order to highlight this role we define an index of market sentiments, which we call "animal spirits", and which reflects how optimistic or pessimistic these forecasts are.

The definition of animal spirits is as follows:

$$
S_{t}=\left\{\begin{array}{cc}
\alpha_{e, t}-\alpha_{f, t} & \text { if } y_{t-1}>0 \\
-\alpha_{e, t}+\alpha_{f, t} & \text { if } y_{t-1}<0
\end{array}\right.
$$

where $S_{t}$ is the index of animal spirits. This can change between -1 and +1 . There are two possibilities:

- When $y_{t-1}>0$, extrapolators forecast a positive output gap. The fraction of agents who make such a positive forecasts is $\alpha_{e, t}$. Fundamentalists, however, then make a pessimistic forecast since they expect the positive output gap to decline towards the equilibrium value of 0 . The fraction of agents who make such a forecast is $\alpha_{f, t}$. We subtract this fraction of pessimistic forecasts from the fraction $\alpha_{e, t}$ who make a positive forecast. When these two fractions are equal to each other (both are then 0.5) market sentiments (animal spirits) are neutral, i.e. optimists and pessimists cancel out and $S_{t}=0$. When the fraction of optimists $\alpha_{e, t}$ exceeds the fraction of pessimists $\alpha_{f, t}, S_{t}$ becomes positive. As we will see, the model allows for the possibility that $\alpha_{e, t}$ moves to

1. In that case there are only optimists and $S_{t}=1$.

- When $y_{t-1}<0$, extrapolators forecast a negative output gap. The fraction of agents who make such a negative forecasts is $\alpha_{e, t}$. We give this fraction a negative sign. Fundamentalists, however, then make an optimistic forecast since they expect the negative output gap to increase towards the equilibrium value of 0 . The fraction of agents who make such a forecast is $\alpha_{f, t}$. We give this fraction of optimistic forecasts a positive sign. When these two fractions are equal to each other (both are then 0.5 ) market sentiments 
(animal spirits) are neutral, i.e. optimists and pessimists cancel out and $S_{t}=0$. When the fraction of pessimists $\alpha_{e, t}$ exceeds the fraction of optimists $\alpha_{f, t} S_{t}$ becomes negative. The fraction of pessimists, $\alpha_{e, t}$, can move to 1 . In that case there are only pessimists and $S_{t}=-1$.

We can rewrite (23) as follows:

$$
S_{t}=\left\{\begin{array}{cc}
\alpha_{e, t}-\left(1-\alpha_{e, t}\right)=2 \alpha_{e, t}-1 & \text { if } y_{t-1}>0 \\
-\alpha_{e, t}+\left(1-\alpha_{e, t}\right)=-2 \alpha_{e, t}+1 & \text { if } y_{t-1}<0
\end{array}\right.
$$

Finally it should be noted that there is a relation between our index of animal spirits $S_{t}$ and the forecast errors chartists and fundamentalists make ${ }^{1}$. We show this in appendix.

\subsection{Solving the model}

The solution of the model is found by first substituting (3a) into (1a) and rewriting in matrix notation. This yields:

$$
\begin{aligned}
& {\left[\begin{array}{cc}
1 & -b_{2} \\
-a_{2} c_{1} & 1-a_{2} c_{2}
\end{array}\right]\left[\begin{array}{l}
\pi_{t}^{\prime} \\
y_{t}
\end{array}\right]} \\
& =\left[\begin{array}{cc}
b_{1} & 0 \\
-a_{2} & a_{1}
\end{array}\right]\left[\begin{array}{c}
\widetilde{\mathrm{E}}_{\mathrm{t}} \pi_{t+1}^{\prime} \\
\widetilde{\mathrm{E}}_{\mathrm{t}} y_{t+1}
\end{array}\right]+\left[\begin{array}{cc}
1-b_{1} & 0 \\
0 & 1-a_{1}
\end{array}\right]\left[\begin{array}{c}
\pi_{t-1}^{\prime} \\
y_{t-1}
\end{array}\right]+\left[\begin{array}{c}
0 \\
a_{2} c_{3}
\end{array}\right] r_{t-1}^{\prime}+\left[\begin{array}{c}
\eta_{t} \\
a_{2} u_{t}+\varepsilon_{t}
\end{array}\right]
\end{aligned}
$$

i.e.

$$
A Z_{t}=B \widetilde{E_{t}} Z_{t+1}+C Z_{t-1}+b r_{t-1}^{\prime}+v_{t}
$$

where bold characters refer to matrices and vectors. The solution for $\boldsymbol{Z}_{\boldsymbol{t}}$ is given by

$$
Z_{t}=A^{-1}\left[B \widetilde{E_{t}} Z_{t+1}+C Z_{t-1}+b r_{t-1}^{\prime}+v_{t}\right]
$$

The solution exists if the matrix $\boldsymbol{A}$ is non-singular, i.e. $\left(1-a_{2} c_{2}\right)-a_{2} b_{2} c_{1} \neq 0$. The system (26) describes the solutions for $y_{t}$ and $\pi_{t}^{\prime}$ given the forecasts of $y_{t}$ and $\pi_{t}^{\prime}$. The latter have been specified in equations (7) and (17) and therefore can be substituted into (26). Finally, the solution for $r_{t-1}^{\prime}$ is found by substituting $y_{t}$ and $\pi_{t}$ obtained from (26) into (3a).

The model has non-linear features making it difficult to arrive at analytical solutions. That is why we will use numerical methods to analyze its dynamics. In

\footnotetext{
${ }^{1}$ The existence of such a relationship was pointed out to us by a referee of our paper.
} 
order to do so, we have to calibrate the model, i.e. to select numerical values for the parameters of the model. In Table 1 the parameters used in the calibration exercise are presented. The values of the parameters are based on what we found in the literature (see Gali(2008) for the demand and supply equations and Blattner and Margaritov(2010) for the Taylor rule). The model was calibrated in such a way that the time units can be considered to be quarters. The three shocks (demand shocks, supply shocks and interest rate shocks) are independently and identically distributed (i.i.d.) with standard deviations of $0.5 \%$. These shocks produce standard deviations of the output gap and inflation that mimic the standard deviations found in the empirical data using quarterly observations for the US and the Eurozone. We describe the procedure that led us to select standard deviations of $0.5 \%$ in Appendix C.

\section{Table 1: Parameter values of the calibrated model}

\begin{tabular}{ll}
\hline $\mathrm{a} 1=0.5$ & coefficient of expected output in output equation \\
$\mathrm{a} 2=-0.2$ & interest elasticity of output demand \\
$\mathrm{b} 1=0.5$ & coefficient of expected inflation in inflation equation \\
$\mathrm{b} 2=0.05$ & coefficient of output in inflation equation \\
$\mathrm{c} 1=1.5$ & coefficient of inflation in Taylor equation \\
$\mathrm{c} 2=0.5$ & coefficient of output in Taylor equation \\
$\mathrm{c} 3=0.8$ & interest smoothing parameter in Taylor equation \\
$\gamma=2$ & intensity of choice parameter \\
$\sigma_{\varepsilon}=0.5$ & standard deviation shocks output \\
$\sigma_{\eta}=0.5$ & standard deviation shocks inflation \\
$\sigma_{u}=0.5$ & standard deviation shocks Taylor \\
$\rho=0.5$ & measures the speed of declining weights in mean squares errors \\
& (memory parameter) \\
\hline
\end{tabular}

\section{Inflation targeting and the zero lower bound}

In this section we present the results of simulating the model for different values of the inflation target (going from $0 \%$ to $4 \%$ ), and imposing a zero lower bound (ZLB) on the nominal interest rate:

$$
r_{\mathrm{t}} \geq 0
$$

Without the ZLB condition, the central bank is able to adjust its nominal interest rate to achieve a real interest rate that stabilizes the output gap. However, with the ZLB condition, the ability of the central bank to stabilize the output gap (especially a negative one) is very much hindered. 
We start by presenting the results using an inflation target of $2 \%$. This will allow us to understand the main features of the model. We then present the results for alternative levels of the inflation target.

\subsection{The basic results}

We simulated the model over 2,000 periods. (This will be the general length of the simulation runs. In a few cases we will increase this length to 10,000 to raise the precision). We present the results in the time domain and in the frequency domain. Figure 1 shows the movements of the output gap and animal spirits in the time domain (left hand side panels). We selected a sample of 200 periods (quarters) that is representative of the full simulation. The right hand side panel shows the output gap and animal spirits in the frequency domain for the full 2,000 periods. We observe that the model produces waves of optimism and pessimism (animal spirits) that can lead to a situation where everybody becomes optimist $\left(S_{t}=1\right)$ or pessimist $\left(S_{t}=-1\right)$. These waves of optimism and pessimism are generated endogenously and arise because optimistic (pessimistic) forecasts are self-fulfilling and therefore attract more agents into being optimists (pessimists).

As can be seen from the left hand side panels, the correlation of these animal spirits and the output gap is high. In the simulations reported in Figure 1 this correlation reaches 0.94 . Underlying this correlation is the self-fulfilling nature of expectations. When a wave of optimism is set in motion, this leads to an increase in aggregate demand (see equation (1)). This increase in aggregate demand leads to a situation in which those who have made optimistic forecasts are vindicated. This attracts more agents using optimistic forecasts. This leads to a self-fulfilling dynamics in which most agents become optimists. It is a dynamics that leads to a correlation of the same beliefs. The reverse is also true. A wave of pessimistic forecasts can set in motion a self-fulfilling dynamics leading to a downturn in economic activity (output gap). At some point most of the agents have become pessimists. 
Figure 1: Output gap and animal spirits in time and frequency domains
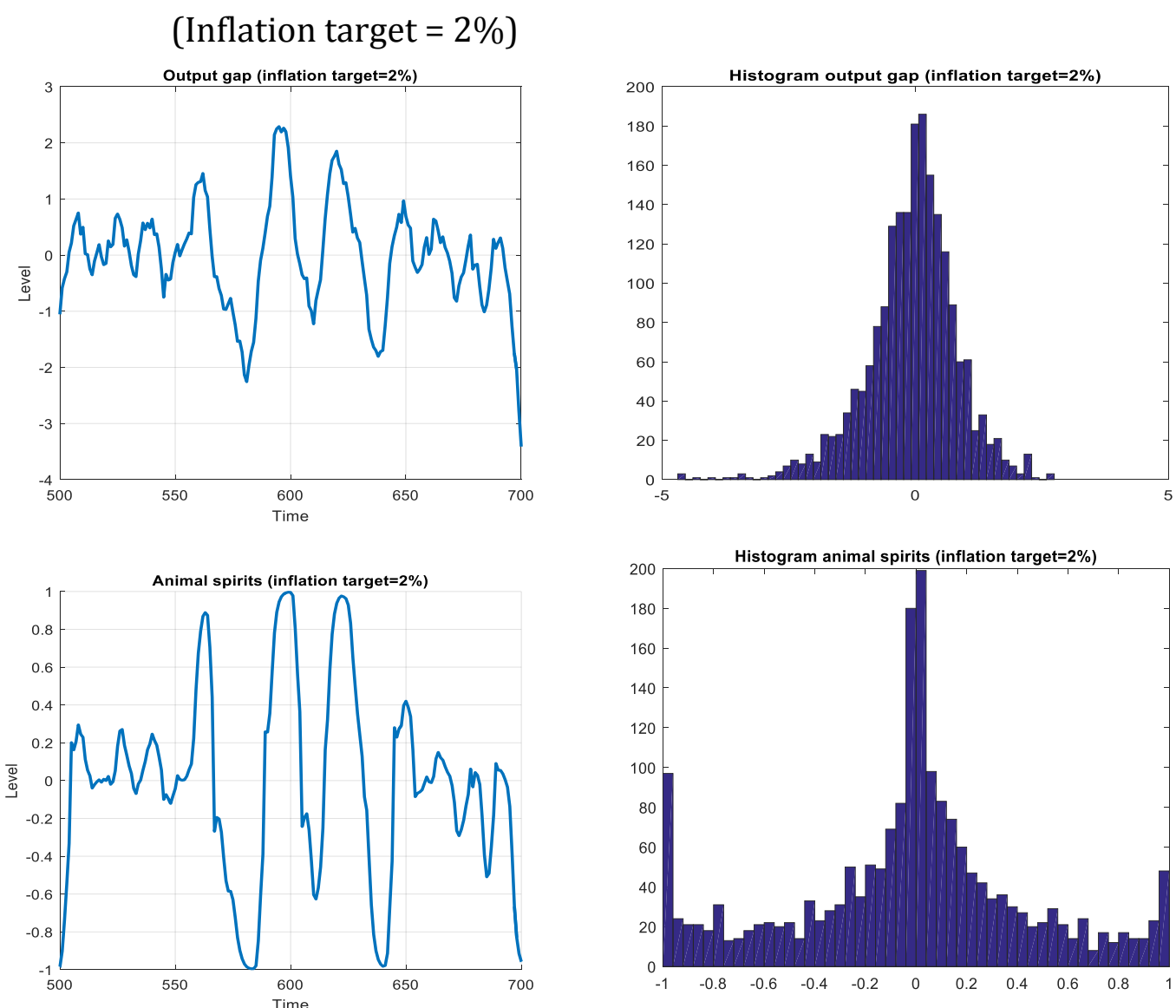

Note: LHS shows simulated output gap and animal spirits in time domain, RHS in frequency domain when inflation target is $2 \%$. The distribution of output gap has fat tails and excess kurtosis and is slightly skewed.

Frequency ZLB-hits = 26\%; mean ZLB-spell=4.8 quarters.

The right hand side panels show the frequency distribution of output gap and animal spirits. We find that the output gap is not normally distributed, with excess kurtosis and fat tails. We find a kurtosis $=4$ which is too high for a normal distribution. A Jarque-Bera test rejects normality of the distribution of the output gap. The origin of the non-normality of the distribution of the output gap (excess kurtosis and fat tails) can be found in the distribution of the animal spirits. We find that there is a concentration of observations of animal spirits around 0 . This means that much of the time there is no clear-cut optimism or pessimism. We can call these "normal periods". There is also, however, a concentration of extreme values at either -1 (extreme pessimism) and +1 (extreme optimism). These extreme values of animal spirits explain the fat tails observed in the distribution of the output gap. The interpretation of this result is as follows. 
When the market is gripped by a self-fulfilling movement of optimism (or pessimism) this can lead to a situation where everybody becomes optimist (pessimist). This then also leads to an intense boom (bust) in economic activity.

In De Grauwe(2012) and De Grauwe and Ji(2016) empirical evidence is provided indicating that observed output gaps in industrial countries exhibit excess kurtosis and fat tails (see also Fagiolo, et al. (2008) and Ascari, et al(2015)), and that the output gaps are highly correlated with empirical measures of animal spirits. Our model mimics these empirical observations and is particularly suited to understand the nature of business cycles, which is characterized by periods of "tranquility", alternated by periods of booms and busts. We return to the empirical validation of the model in section 6 .

In order to improve understanding of the model it is also useful to relate the fractions of extrapolators and fundamentalists to the performance (utility) of these rules (as measured by the negative of the forecast errors). We do this in Figures A2 to A4 (see Appendix B). We observe the strong correlation of the relative performance of the extrapolating rule versus the fundamentalist rule (measured by the difference in utilities of using these rules) and the fraction of the agents using the extrapolating rule.

It is also important to understand the nature of forecasting in this model by focusing on the systematic patterns in the forecasting errors. Using the simulation over 2,000 periods reported in Figure 1, we find that there is autocorrelation in the forecasting errors. For the output gap this autocorrelation is 0.37 , while for inflation this is 0.15 . We also find that the standard deviations of these forecasting errors amounts to 0.60 in the case of the output gap and 0.5 in the case of inflation, and that there is a small negative correlation of -0.2 between the forecasting errors of the output gap and of inflation. We note that there is some variation in these numbers as they depend on the realization of the stochastic shocks. We therefore decided to increase the length of the simulation run to 10,000 and found that these numbers converge to 0.35 and 0.14 for the autocorrelations in the forecasting errors in output gap and inflation. The standard deviations of the forecasting errors in output gap and inflation converge to 0.62 and 0.49 . Finally, the correlation between the forecasting errors 
of the output gap and inflation settled at -0.15 . In the empirical section 6.4 we compare these theoretical forecast errors with those obtained using the Survey of Business Forecasts (SBF) of the European Central Bank.

Finally, we computed the correlation between the probabilities of being a fundamentalist for the output gap and a fundamentalist for inflation the fractions $\alpha_{f, t}$ and $\beta_{\text {tar }, t}$ defined in (12) and (19), respectively). We find that this correlation is approximately 0.3 (depending on the realization of the stochastic shocks). Thus, despite the assumption of independence in the selection of the forecasting rules, the realized choices generated from our model are actually correlated. This is due to the interactions of the different variables in the model.

We now ask the question of how the results shown in Figure 1 are affected by the level of the inflation target chosen by the central bank. We start by noting that the output gap in Figure 1 is slightly skewed to the left. In fact the skewness is found to be -0.66 . This skewness finds its origin in the fact that the distribution of animal spirits is also skewed to the left, i.e. there are more periods of pessimism than optimism. We find that on average animal spirits are negative $(-0.03)$. We also find that the interest rate is hitting the ZLB $26 \%$ of the time and that the mean ZLB-spell is 4.8 quarters.

In order to evaluate the importance of the inflation target we simulated the model under two alternative and extreme assumptions of the inflation targets. In the first one we set the inflation target equal to $0 \%$; in the second one to $4 \%$. We show the results in Figures 2 and 3.

Our major findings are the following. We observe from Figure 2 that when the inflation target is zero we obtain a very skewed distribution of output gap and animal spirits (skewness is -0.96 and mean animal spirits is -0.22). Most of the time animal spirits are negative with many periods of extreme pessimism. There are very few periods of optimism. This can also be seen from the simulations in the time domain: the output gap is negative most of the time and animal spirits are also negative most of the time. The probability of hitting the ZLB is $64 \%$ and once the ZLB is hit the mean length of staying in the ZLB is more than 9 quarters. Thus it can be concluded when the central bank sets an inflation target equal to 
zero pessimism prevails most of the time and recession is a chronic feature of the business cycle with very few periods of optimism.

We obtain very different results with an inflation target of $4 \%$. The results are presented in Figure 3. We now find that the distributions of the output gap and animal spirits are symmetric. Skewness of output gap is not statistically different from 0 and animal spirits are 0 on average. Periods of optimism and pessimism occur equally frequently. The number of times the ZLB is hit is less than $10 \%$ and the mean length of a ZLB-spell has dropped to 3.2 quarters.

\section{Figure 2: Output gap and animal spirits in time and frequency domains} (Inflation target $=0 \%$ )
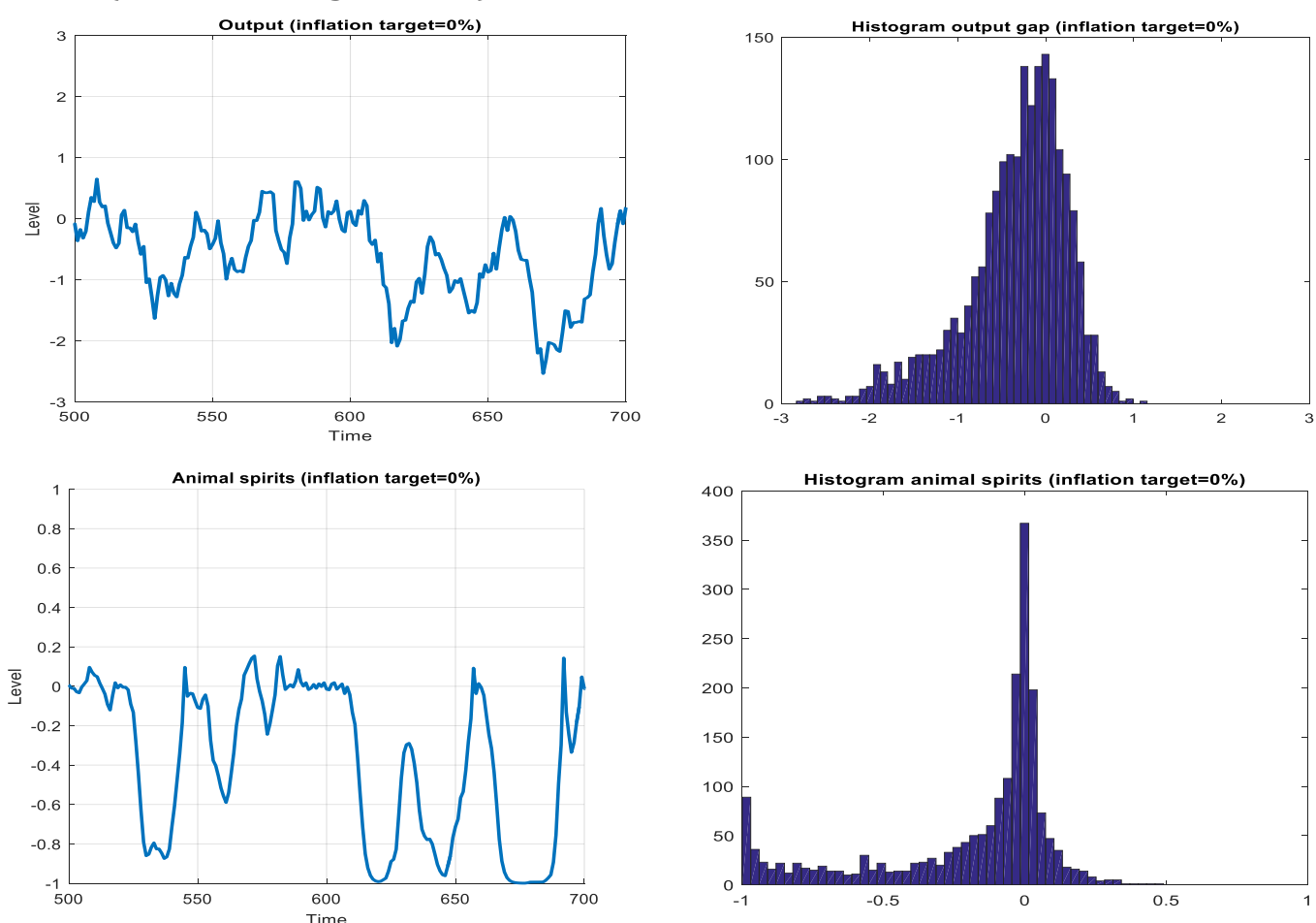

Note: LHS shows simulated output gap and animal spirits in time domain, RHS in frequency domain when inflation target is $0 \%$. Distribution output gap and animal spirits negatively skewed Frequency ZLB-hits = 64\%; mean ZLB-spell=9.1 quarters 
Figure 3: Output gap and animal spirits in time and frequency domains

(Inflation target $=4 \%$ )
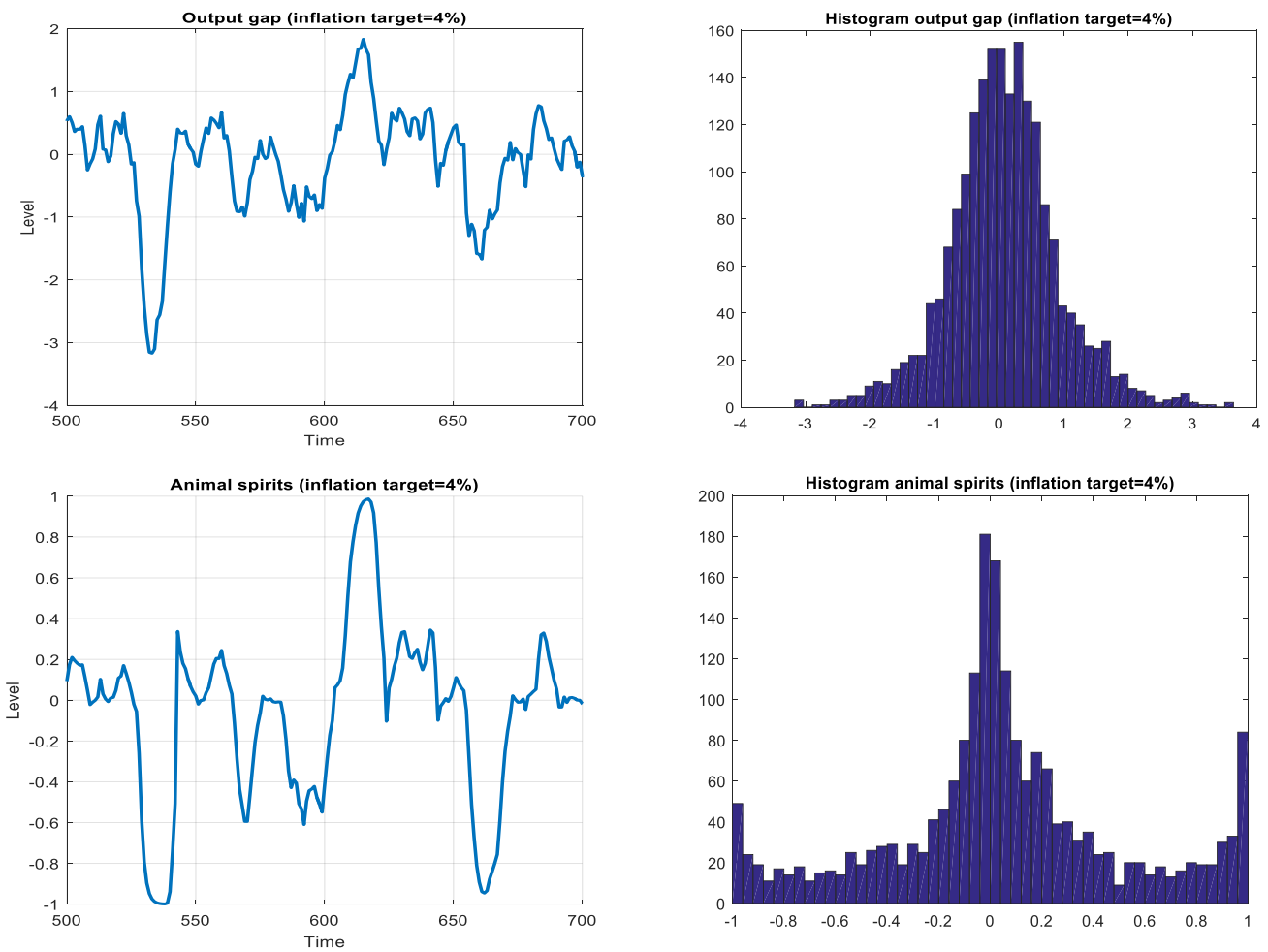

Note: LHS shows simulated output gap and animal spirits in time domain, RHS in the frequency domain when inflation target is $4 \%$. Symmetric distribution of output gap and animal spirits.

Frequency ZLB-hits = 9\%; mean ZLB-spell=3.2 quarters

In order to obtain a more precise idea about the relation between inflation target and the asymmetry in the distribution of output gap and animal spirits we computed the skewness of the distribution of output gap and the mean animal spirits for different values of the level of the inflation target. We show the results in Figures 4 and 5 (Note that the length of the simulation runs is 2,000 periods). From Figure 4 we conclude that as the inflation target increases the skewness of the distribution of the output gap declines. It reaches values close to 0 when the inflation target is $3 \%$. We note the non-linear relation between inflation target and skewness. With an inflation target equal to $2 \%$ skewness is reduced substantially but there is still a significant amount of skewness, suggesting that an inflation target of $2 \%$ may not be optimal. We return to the question of optimality in the next section. 
Figure 5 shows the relation between inflation target and the mean animal spirits. We find that when the inflation target increases the mean value of animal spirits increases in a non-linear way. Put differently with increasing inflation target (starting from 0\%) endemic pessimism is reduced significantly. When the inflation target reaches 3\% animal spirits are zero on average, i.e. periods of optimism and pessimism are equally probable.

Figure 4:

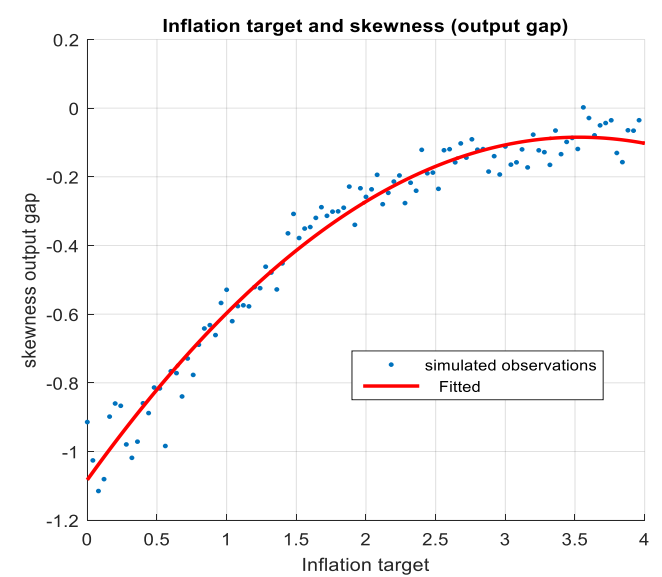

Figure 5

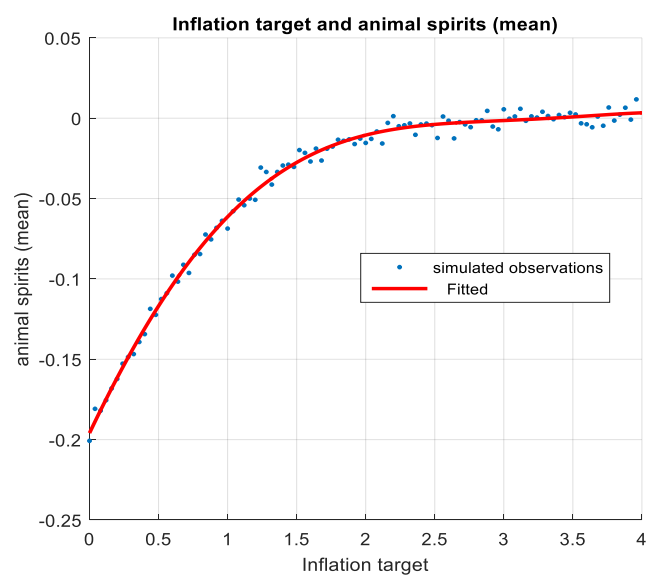

Note: An increase of the inflation target reduces the negative skewness of the output gap and reduces pessimism (negative animal spirits)

How can these results be interpreted? When the inflation target is $0 \%$ the cyclical movements in output gap and animal spirits inevitably lead to recessions that also drive inflation into negative territory. When that happens the zero bound constraint that applies to the nominal interest rates makes it impossible for the central bank to lower the real interest rate. If the recession is deep and deflation intense the real interest rate is likely to increase significantly. Thus the recession becomes protracted. Pessimism sets in and amplifies the recession, and validates pessimism. As the central bank loses its stabilizing capacity the economy gets stuck in pessimism, recession and deflation. We conclude that an inflation target of $0 \%$ becomes a breeding ground for pessimism and recession. The way out is to increase the inflation target. Our results suggest that an inflation target of $3 \%-4 \%$ is probably better than $2 \%$ in making sure that the economy does not get stuck in the chronic pessimism trap. 
Finally we also looked at the number of times the zero lower bound was hit for different levels of the inflation target. We show the results in Figure 6. On the horizontal axis we show the inflation target; on the vertical axis we present the number of ZLB-hits (In order to increase the precision we raised the length of the simulation runs to 10,000 periods). We observe a non-linear relationship: when the inflation target is $0 \%$ the number of times the ZLB is hit exceeds $60 \%$. The number of hits then declines when the inflation target is raised. Note that when the inflation target is $2 \%$ we hit the ZLB about $26 \%$ of the time. In that case we find that the typical length of a ZLB-episode is 5 quarters.

\section{Figure 6}

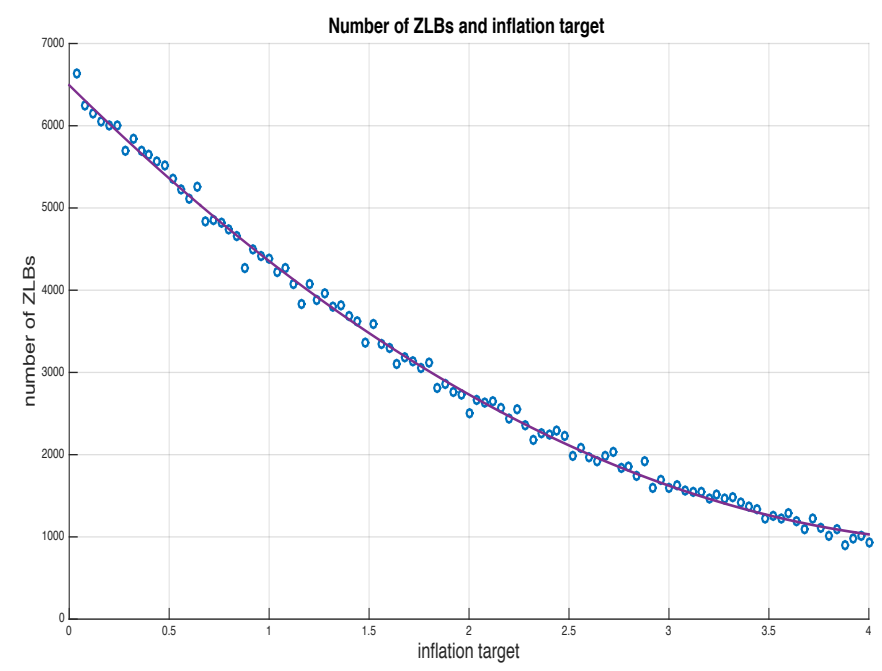

Note: An increase in the inflation target reduces the probability of hitting the ZLB

\subsection{The role of animal spirits}

What is the importance of animal spirits in creating skewness in the output gap? The way we want to answer this question is to compare the results of the behavioral model with the three-equations New Keynesian model (aggregate demand, aggregate supply and Taylor rule) solved under rational expectations (RE). We know that in a RE-model animal spirits play no role. A comparison of our behavioral model where animal spirits play a central role with the same structural model under rational expectations will allow us to isolate the role of animal spirits.

We used the model consisting of equations (1a) to (3a) and solved these under rational expectations imposing a zero lower bound on the nominal interest rate. 
We assumed the same parameters and the same distribution of shocks as in the behavioral model. We simulated the model for different levels of the inflation target (from $0 \%$ to $4 \%$ ). We show the results in Figure 7 . This presents the simulated output gaps in the frequency domain. We observe that with an inflation target of $0 \%$ the distribution has a negative skewness (-0.37). This skewness tends to decline as the inflation target is raised. When the inflation target is $4 \%$, the skewness in the distribution of the output gap is not significantly different from zero. When comparing these results with those obtained in the behavioral model (Figures 1 to 3 ) we find that the degree of skewness is much less pronounced in the rational expectations model than in the behavioral model.

Figure 7: Frequency distribution output gap in rational expectations model

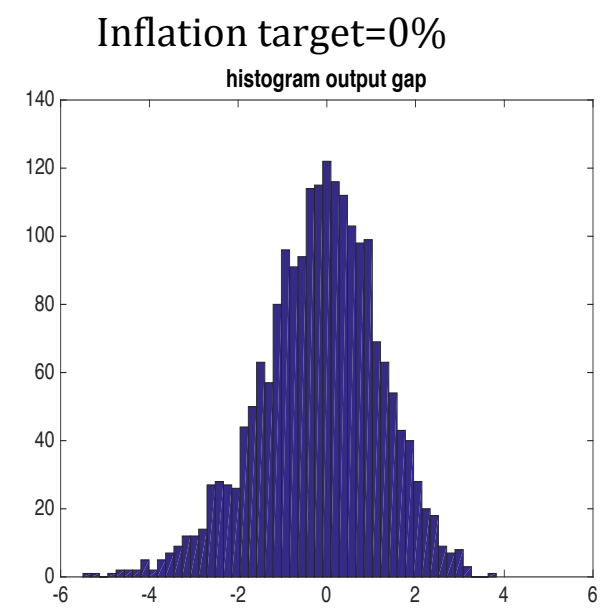

Skewness $=-0.37$

$\mathrm{ZLB}=47 \%$; mean ZLB-spell=3.1
Inflation target $=2 \%$

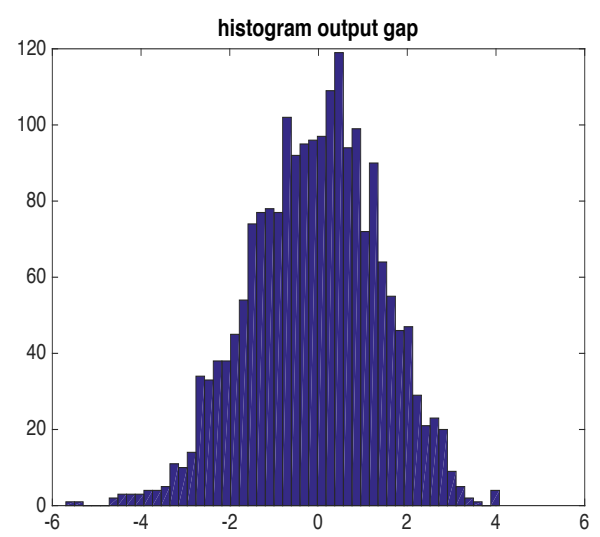

Skewness $=-0.20$

ZLB = 8\%; mean ZLB-spell=1.6

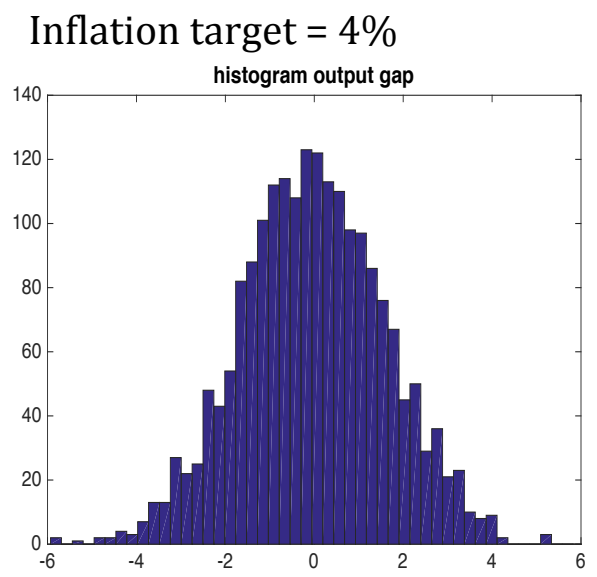

Skewness $=0.01$

$\mathrm{ZLB}=0.5 \%$; mean ZLB-spell=1.3 
Note: Skewness distribution of output gap in RE-model is less pronounced than in behavioral model. As in behavioral model it declines with the level of inflation target.

We also computed the number of ZLB-hits and the mean length of time of ZLBepisodes in the RE-model. These are shown below the charts of Figure 7. With an inflation target of $0 \%$ the number of ZLB-hits is $47 \%$ (versus $64 \%$ in the behavioral model). It declines sharply when the inflation target increases $(8 \%$ ZLB-hits when inflation target=2\% (versus $26 \%$ in the behavioral model), and $0.5 \%$ ZLB-hits when inflation target $=4 \%$ (versus $9 \%$ in behavioral model). We find that in each of these cases the number of ZLB-hits is lower than in the behavioral model (see Figure 6).

This difference between the RE-model and the behavioral model is equally pronounced for the mean length of ZLB-episodes. In the RE-model, these are 3.1, 1.6 and 1.3 quarters compared to 9.1, 4.8, and 3.2 quarters in the behavioral model, for inflation targets increasing from $0 \%$ to $4 \%$. These results lead to the conclusion that by amplifying the movements of the output gap, animal spirits push the output gap more frequently and keep it longer in negative territory than in a RE-model. As a result, animal spiritis produce more protracted economic downturns when the inflation target is set too low than what is obtained in a RE-model.

\section{Impulse responses to demand and supply shocks}

In this section we compute impulse responses to demand and supply shocks assuming different levels of inflation target. We will assume two different inflation targets $0 \%$ and $4 \%$ (the $2 \%$ inflation target regime is intermediate between these two extremes). These impulse responses are expressed as "multipliers", i.e. the output responses to the shock are divided by the shock itself (which is two standard deviations of the error terms in the demand and supply equations).

In contrast to linear rational expectations models the impulse responses depend on the timing of the shock. Put differently, an impulse response computed with 
one realization of the stochastic shocks in the equations of the model will be different from an impulse response to exactly the same shock but performed using another realization of these stochastic shocks. This is the case even when all parameters of the model are identical.

In order to illustrate this we simulated 1000 impulse responses to the same shock (demand respectively supply), assuming each time a different realization of stochastic shocks. We then computed the mean response obtained from these 1000 impulse responses together with the impulse responses two standard deviations above and below the mean response. The results are shown in Figures 8 and 9 for the demand shock and Figure 10 for the supply shock. We show the results for two inflation target regimes, $0 \%$ and $4 \%$.

\subsection{Impulse responses to a negative demand shock}

We first discuss the impulse responses to the negative demand shock ${ }^{5}$. (Figure 8). Two results stand out. First, there is great uncertainty about the transmission of a shock even if the parameters of the model are known with certainty, as this transmission depends on "initial conditions", i.e. on the configuration of stochastic disturbances that prevail at the moment the demand shock occurs. For example, the effect of the demand shock may be very different depending on whether the shock occurs during a recession, a boom or in more normal business cycle conditions. Thus, in our model the timing of the shock matters. We also note that this uncertainty is more pronounced in the $0 \%$ inflation targeting regime than in the $4 \%$ regime.

Figure 8: Impulse responses to negative demand shock
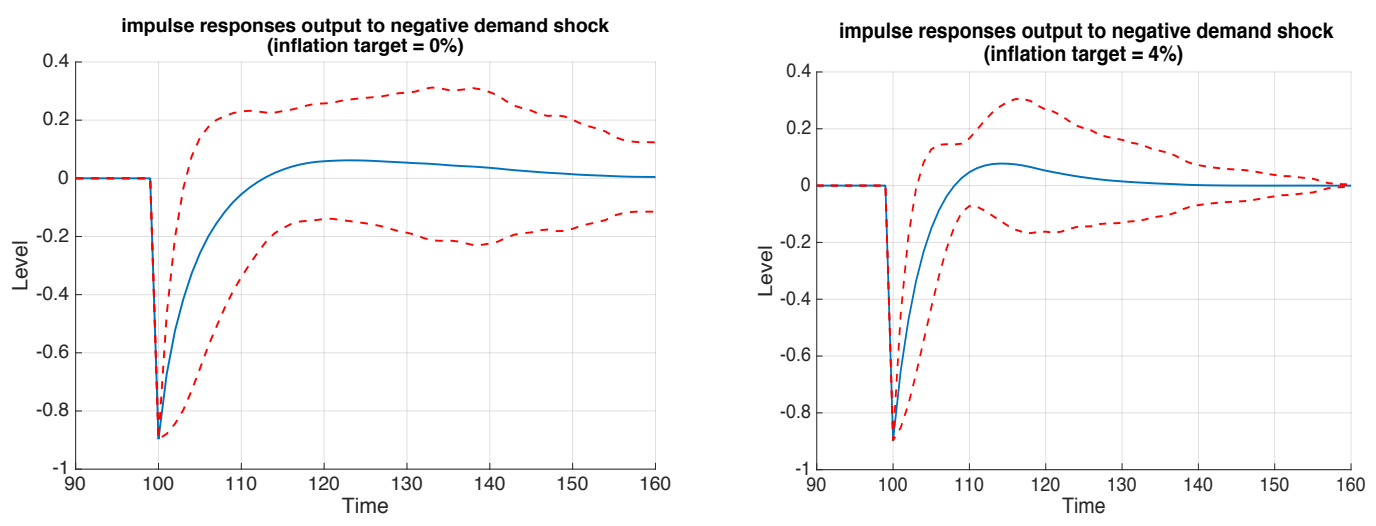

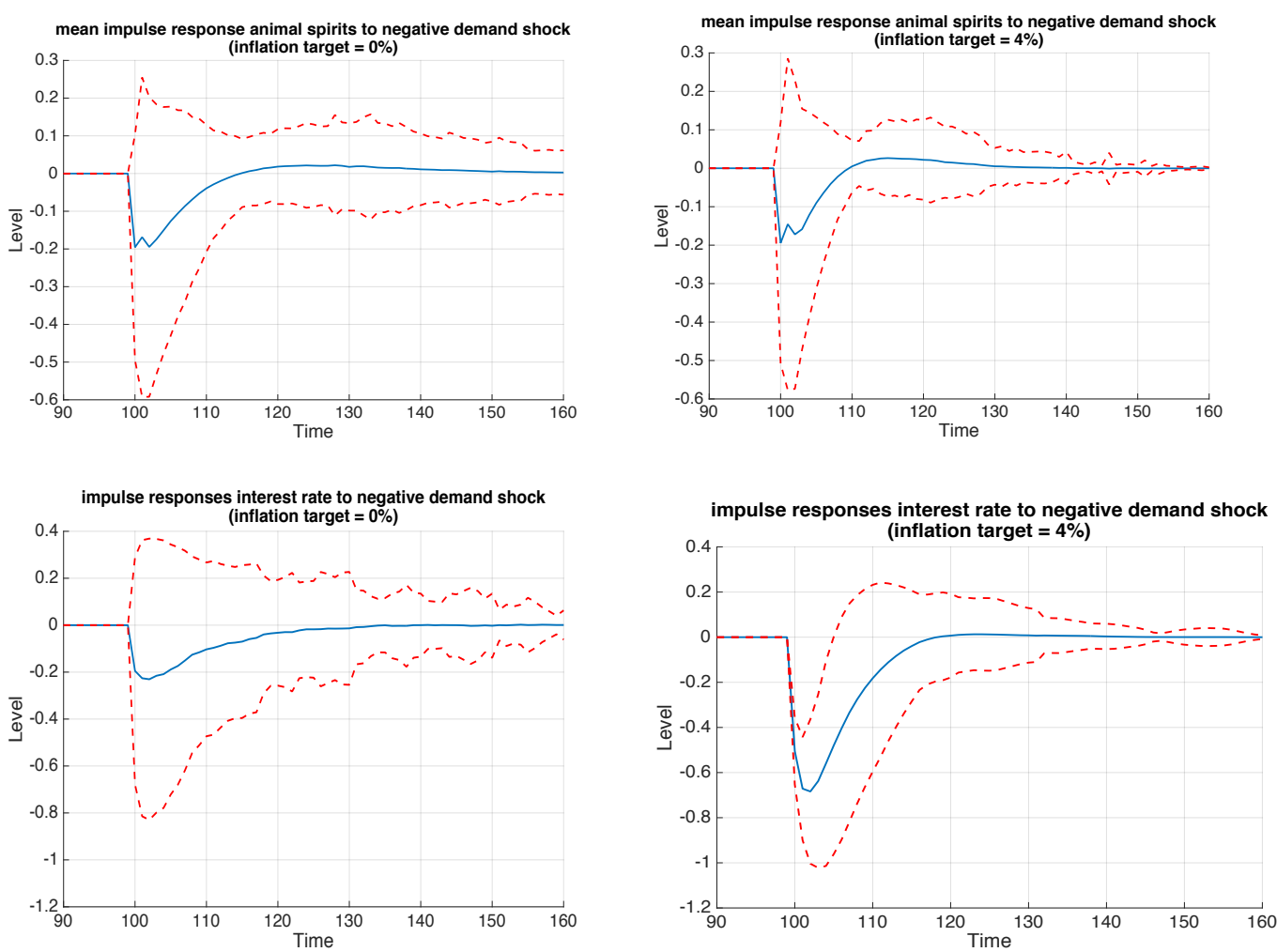

Note: With high inflation target economic recovery is faster after initial negative demand shock

Second, after the initial negative demand shock, the output gap recovers more quickly and animal spirits become neutral faster when the inflation target is $4 \%$ than when it is $0 \%$. We observe that in the $4 \%$ inflation target regime, the output gap reaches zero after 8 quarters, while it takes 12 quarters for the output gap to reach zero in the $0 \%$ inflation target regime. For the animal spirits it takes 15 quarters to become neutral in the latter regime as compared to 10 quarters in the $4 \%$ inflation target regime. Thus, when the inflation target is set at $4 \%$ the economy recovers faster from a negative demand shock than when the inflation target is set at the low level of $0 \%$. This difference is of course associated with the fact that in a $4 \%$ inflation target regime there is more scope for the central bank to stabilize the business cycle by lowering the interest rate (see last two charts in Figure 8).

It will be useful to focus on the short-term impulse responses of the demand shock. The way we do this is by presenting the frequency distributions of the short-term effects of the demand shock. These frequency distributions are obtained by collecting the impulse responses obtained in the $4^{\text {th }}$ quarter after the 
shock occurred. In so doing we obtained 1000 short-term output responses and 1000 short-term responses of animal spirits. We plot these in the frequency domain. The results are shown in Figure 9.

The most striking result in Figure 9 is the fact that when the inflation target is high $(4 \%)$ the negative impact on output following a negative demand shock is significantly lower, on average, than when the inflation target is low (0\%). At the same time, the short-term responses in animal spirits are on average more negative with a low inflation target than with a high one. But as mentioned earlier, there is a wide variation in the short-term effect of the same demand shock on output and animal spirits. This variation tends to be higher when the inflation target is low.

Focusing on the short-term interest rate responses, we find that when the inflation target is zero, the interest rate response to the negative demand shock is zero in more than half of the cases (1000 replications of the same shock). In other words when the inflation target is zero the negative demand shock leads the interest rate to hit the ZLB in more than half of the cases. When the inflation target is $4 \%$ the number of ZLB-hits almost completely disappears.

The mechanism that drives these results is the same as the one we unveiled in the previous sections. With a zero inflation target there is little scope for output stabilization following a negative demand shock because the interest rate is very likely to hit the ZLB. As a result, this shock will have a stronger negative output effect in a low inflation target environment as compared with a high inflation target environment. Animal spirits amplify these differences. When the inflation target $=0 \%$ the negative demand shock together with the inability of the central banks to stimulate output by reducing the interest rate creates more pessimism than when the inflation target $=4 \%$ (see figure 8). In the latter case the central bank is capable of stabilizing output. This in turn reduces pessimism and reinforces the stabilization effort of the central bank. 
Figure 9: Frequency distribution of short-term responses to negative demand shock
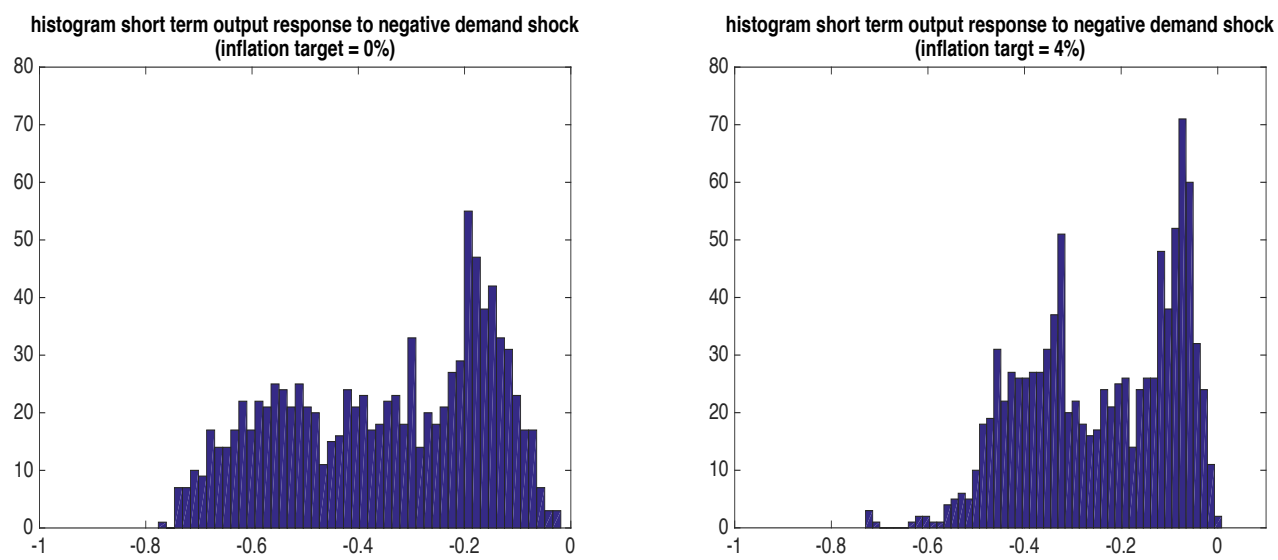

histogram short term animal spirits response to negative demand shock

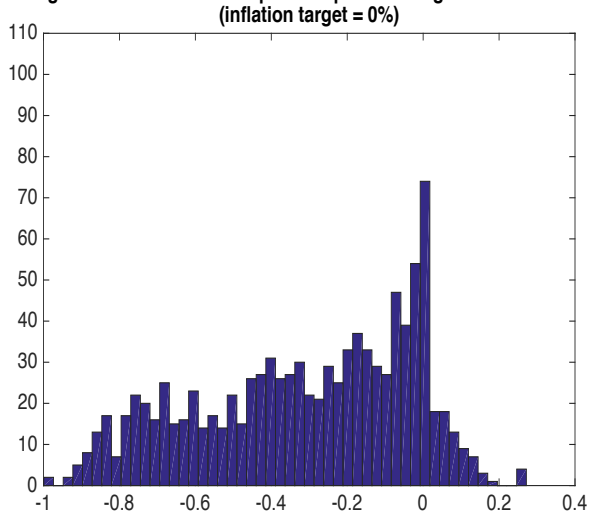

histogram short term animal spirits response to negative demand shock
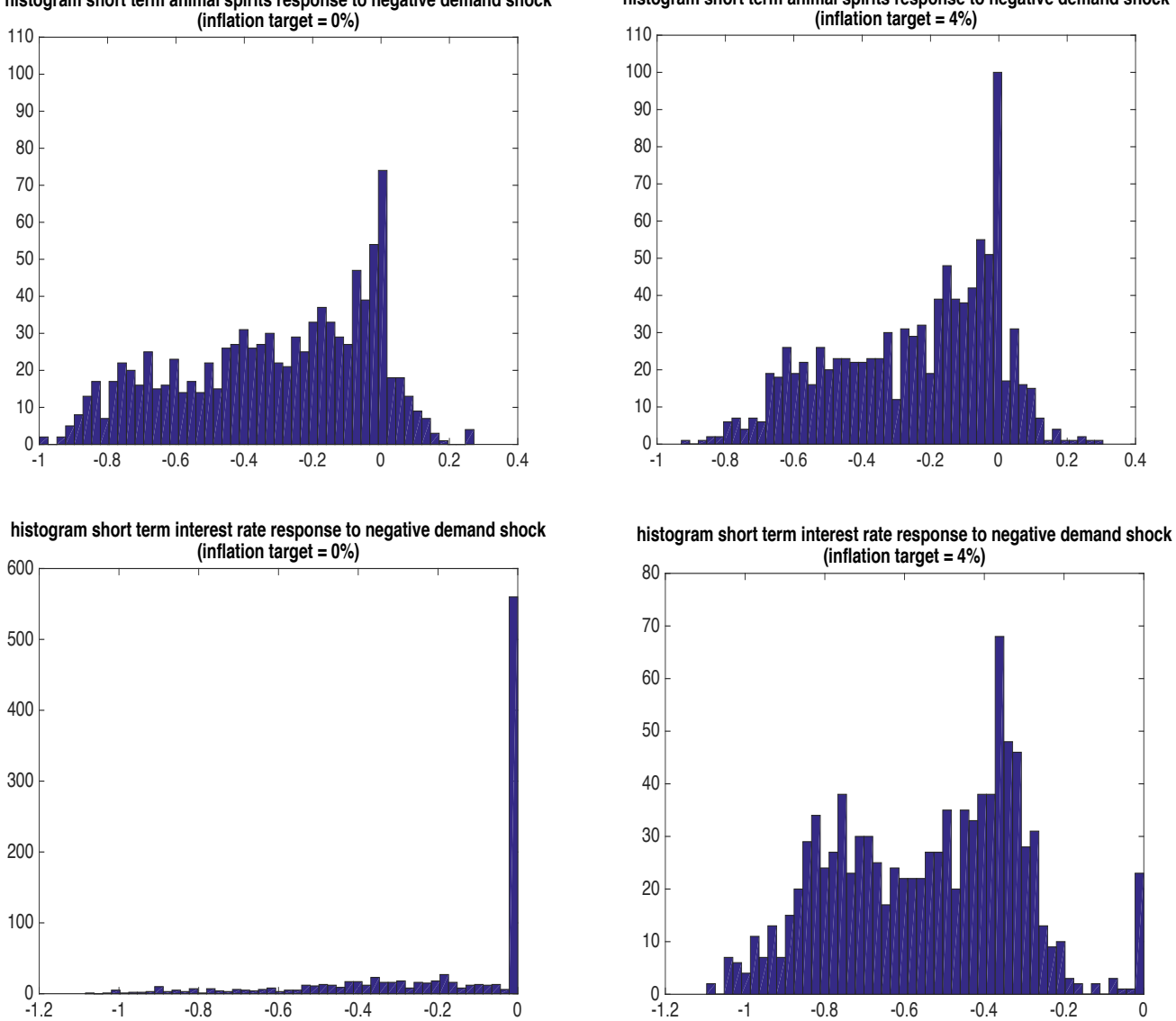

Note: when inflation target is high (4\%) the negative short-term impact on output after negative demand shock is significantly lower, on average, than when the inflation target is low (0\%). There is great uncertainty about this effect. 


\subsection{Impulse responses to a positive supply shock}

In this section we analyze the impulse responses to a positive supply shock ${ }^{6}$. The positive supply shock can be interpreted as a positive shock in productivity, shifting the supply curve downwards and producing a decline in the rate of inflation. An inflation targeting central bank will react to this decline in the rate of inflation by lowering the interest rate. The capacity to do so, however, is limited if the inflation target is low (0\%). It increases when the inflation target is raised. The effects are shown in Figure 10.

We observe that in a regime of high inflation targeting (4\%) the impact of the positive supply shock on the output gap is higher than in the case of low inflation target $(0 \%)$. Similarly, animal spirits become more positive after the supply shock in the high inflation target than in the low inflation target regime.

The underlying mechanism that drives these differences is the different interest rate responses to the positive supply shock. In the high inflation targeting regime the central bank reacts by lowering the interest rate thereby fueling the supply shock. In the low inflation targeting regime the central bank is constrained by the ZLB and is prevented from fueling the supply shock by an expansionary monetary policy.

The two inflation target regimes also differ in the speed with which the system returns to the steady state. In the high inflation target regime the return to the steady state is faster than in the low inflation target regime. This has to do with the fact that the central bank reverses its interest rate policy quicker in the former than in the latter case. This then also has the effect of leading animal spirits out of their "euphoric" state faster in the high inflation as compared to the low inflation target regime. It follows that in the high inflation target regime the capacity of the central bank to steer the economy towards its steady state is better than in the low inflation target regime when a positive supply shock occurs. This is a similar conclusion as the one derived in the previous section. 
Figure 10: Impulse responses to positive supply shock
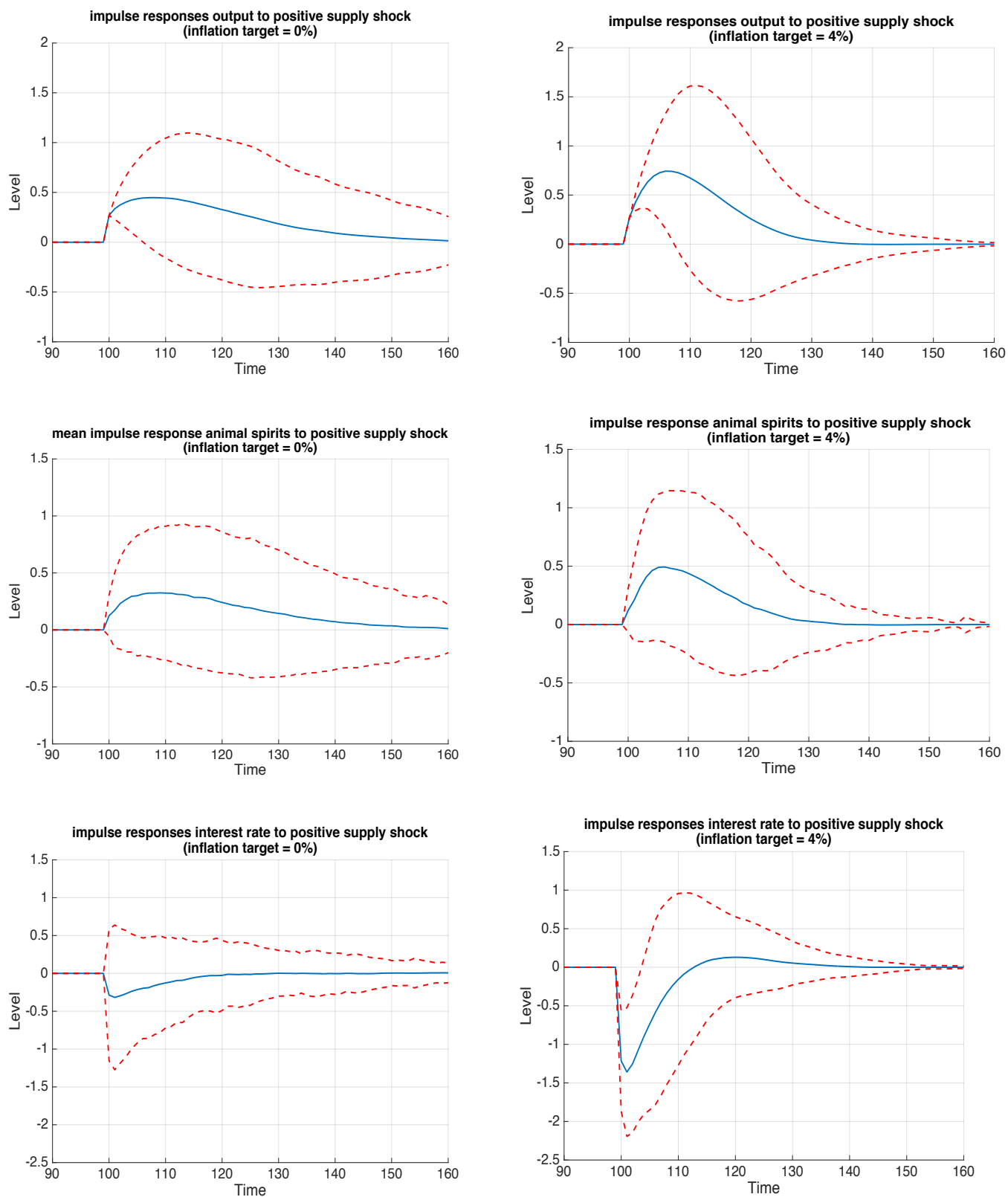

Note: In regime of high inflation targeting (4\%) positive supply shock stimulates output more and creates more optimism than in low inflation target regime $(0 \%)$

\section{Credibility of inflation targeting and the zero lower bound}

An objection to the idea that central banks should adopt a higher inflation target is that this would negatively affect their credibility (see e.g. Branch and Evans(2014)). We analyze this question of credibility in this section.

Our model allows us to give a precise definition of the credibility of the inflation target. This can be defined by the fraction of agents who use the announced 
inflation target as their forecast for future inflation. We have called these agents the "targeters". Since these agents use the announced inflation target as their inflation forecast it can be said that they trust the central bank's inflation commitment. In contrast, the extrapolators do not trust the central bank.

We used this insight to compute an index of inflation credibility, which we define to be the fraction of "targeters", $\beta_{t a r, t}$ as shown in equation (19). We then computed this index for different values of the Taylor output parameter and the inflation target. We show the result in Figure 11.

Two results stand out. First, when the central bank increases its stabilization effort (the Taylor parameter increases) this has the effect of first increasing the inflation credibility of the central bank. When the Taylor output parameter reaches a value of approximately 0.5 further stabilization efforts lead to a decline in inflation credibility. This result can be given the following interpretation. When the central bank starts increasing its stabilization efforts, the central bank also reduces the amplitude of the waves of optimism and pessimism (animal spirits) thereby stabilizing not only output but also inflation. This increases its inflation credibility. When the central bank uses too much output stabilization, however, it undermines its inflation credibility and as a result the credibility decreases. Note that the empirical literature reveals that central banks tend to set the Taylor output parameter close to 0.5. We discuss this result in more details in De Grauwe (2012).

Second, an increase in the inflation target has the effect of shifting the credibility lines upwards, i.e. when the central bank increases its inflation target from $0 \%$ to $4 \%$ its credibility in fighting inflation increases for all values of the Taylor output parameter. Put differently, by increasing the inflation target the central bank improves its inflation credibility regardless of whether the central bank applies little or much output stabilization. This result can be given the following interpretation. When the inflation target is set too low, the rate of inflation is more likely to be pushed into negative territory. This is the territory in which the central bank loses its capacity to influence both inflation and output by varying the interest rate. As result, it will frequently fail to reach its inflation target. By raising the inflation target it reduces the frequency of hitting the zero lower 
bound. As a result, it maintains its capacity to affect inflation and output by varying the interest rate. This is illustrated in Figure 12, which shows the number of times (in simulations of 1000 periods) the ZLB is hit for different values of the Taylor output parameter and levels of inflation target. We observe that raising the intensity of output stabilization reduces the number of times the ZLB is hit for all levels of inflation target. Similarly, raising the inflation target reduces the frequency of hitting the ZLB for all values of the Taylor output parameter.

\section{Figure 11: Credibility and inflation targets}

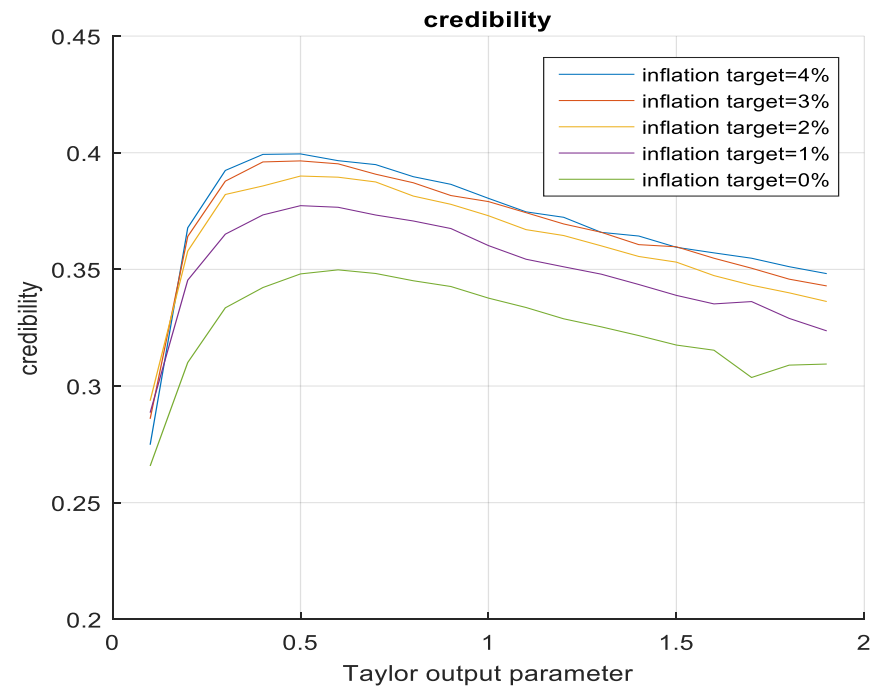

Note: By increasing inflation target the central bank improves its inflation credibility; output stabilization improves inflation credibility up to a point

\section{Figure 12: Number of ZLB periods, stabilization and inflation targets}

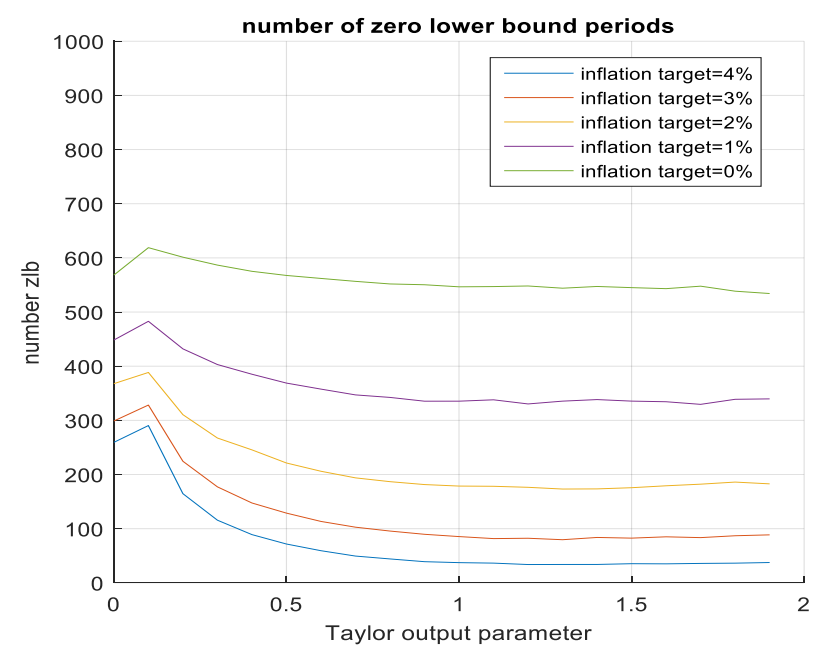

Note: Raising intensity of output stabilization and increasing inflation target reduces frequency of hitting ZLB 


\section{Empirical verification}

In this section we provide empirical verification of some of the predictions made by our behavioral model. We focus on three predictions.

\subsection{Excess kurtosis and fat tails in the distribution of the output gap}

Our model predicts that the distribution of the output gap is non-normal, i.e. it exhibits excess kurtosis and fat tails. The latter are generated when the economy is gripped by extreme optimism or pessimism, leading to large positive or negative movements in output. This feature is also what drives most of our results. The existence of non-normality in the distribution of the output gap (and output growth) has been confirmed empirically for most OECD countries (see Fagiolo, et al., (2008), Fagiolo, et al., (2009), De Grauwe and Ji(2016)). Ascari et al.(2015) find that RBC and NK models cannot generate the fat tails observed in the data (which our paper can).

One could object to this empirical evidence that the large shocks observed in the output gaps can also be the result of large exogenous shocks (see FernandezVillaverde and Rubio-Ramirez(2007) and Justiniano and Primiceri(2008)). The claim that is made here is not that the economy cannot sometimes be hit by large shocks (it often is), but that a theory that can explain large movements in output gaps only as a result of large exogenous shocks is an incomplete one. This creates an opening for a theory like ours that can explain large movements in the output gap (fat tails) endogenously.

\subsection{Two-way causality between animal spirits and output gap}

In our theoretical model, there exists a two-way causality between animal spirits and the output gap, i.e. positive (negative) animal spirits produce a positive (negative) output gap; conversely, a positive (negative) output gap leads to positive (negative) animal spirits. This is in fact a key feature of our theoretical model, which produces a self-reinforcing mechanism that leads to booms and busts, characterized by extreme optimism and pessimism. 
We illustrate this feature in Table 3. We applied Granger causality tests on our simulated output gap (Y) and animal spirits (ANSPIRITS) obtained from simulating our theoretical model. We find that we cannot reject the hypothesis that in our model the output gap Granger causes animal spirits and vice versa.

Table 3: Pairwise Granger Causality Tests (inflation target 4\%)

\begin{tabular}{lcccc}
\hline & \multicolumn{2}{c}{ Lag1 (observation } & 1998) & \multicolumn{2}{c}{ Lag2(observation =1997) } \\
\hline Null Hypothesis: & F-Statistic & Prob. & F-Statistic & Prob. \\
$\begin{array}{l}\text { Y does not Granger Cause } \\
\text { ANSPIRITS }\end{array}$ & 681.507 & 0.0000 & 162.508 & 0.0000 \\
$\begin{array}{l}\text { ANSPIRITS does not Granger } \\
\text { Cause Y }\end{array}$ & 134.629 & 0.0000 & 50.0886 & 0.0000 \\
\hline
\end{tabular}

Note: Granger causality test applied to simulated output gap and animal spirits

In order to test this two-way causality between animal spirits and the output gap, we have to find an empirical counterpart of animal spirits. We decided to use the business confidence index (BCI) as produced by the OECD as an indicator for the animal spirits. The BCI is based on enterprises' assessment of production, orders and stocks, as well as its current position and expectations for the immediate future. This is very similar to what our index of animal spirits $S_{t}$ measures. As will be remembered, when $S_{t}$ is positive it means that the fraction of agents with a positive outlook about the future output gap is larger than the fraction of agents with a negative outlook. This is also what the BCI measures when it questions participants about their sentiments (forecasts) about future business conditions.

The BCI has been rescaled to yield a long-term average of 100 . The more the index exceeds 100, the more optimistic (positive animal spirits) it shows. The more the index is below 100, the more pessimistic (negative animal spirits) it shows. We performed Granger causality tests between the BCI and the output gap for the Eurozone and for the US during the period 1999-2015. The results are shown in Table 4. 
Table 4: Granger causality tests Business Confidence Index (BCI) and output gap (Sample period: 1999Q1- 2015Q4)

\begin{tabular}{llllll}
\hline & & \multicolumn{2}{l}{ Lag=1 (obs=71) } & \multicolumn{2}{c}{ Lag=2 (obs=70) } \\
& Null Hypothesis & F test & Prob. & F test & Prob. \\
\hline U.S. & $\begin{array}{l}\text { Output gap does not } \\
\text { granger cause BCI }\end{array}$ & 6.4923 & 0.0131 & 11.542 & 0.0011 \\
& $\begin{array}{l}\text { BCI does not granger } \\
\text { cause output gap }\end{array}$ & 23.113 & 0 & 23.683 & 0 \\
\hline Eurozone & $\begin{array}{l}\text { Output gap does not } \\
\text { granger cause BCI } \\
\text { BCI does not granger } \\
\text { cause output gap }\end{array}$ & 6.9791 & 0.0102 & 6.4346 & 0.0135 \\
\hline
\end{tabular}

Note: the Dickey-Fuller tests reject unit root in BCI and output gap

Data resources: $\mathrm{BCI}$ is from OECD, output gap is from oxford economics. Data frequency: quarterly. The BCI quarterly data is averaged from monthly data.

We find that we cannot reject the hypothesis of a two-way causality between the output gap and the indicators of business confidence (BCI) in the Eurozone and the US. This confirms one of the key predictions of our model, i.e. the dynamics of booms and busts is characterized by a process by which waves of optimism and pessimism drive the business cycle, while the latter also influences optimism and pessimism.

\subsection{Probabilities of hitting the ZLB}

We noted in the introduction that standard linear DSGE models have tended to underestimate the probability of hitting the ZLB as was shown by Chung, et al., (2012). Most of these models have led to the prediction that when the central bank keeps an inflation target of $2 \%$, it is very unlikely for the economy to be pushed into the ZLB (Reifschneider and Williams (1999), Coenen(2003), Schmitt-Grohe and Uribe(2007) ). Reifschneider and Williams(1999) came to the conclusion that "if monetary policy followed the prescriptions of the standard Taylor rule with an inflation target of 2 percent, the federal funds rate would be near zero about 5 percent of the time (p.1). Our model came to a prediction that when central banks set an inflation target of $2 \%$ and using the same Taylor rule, the probability of hitting the ZLB is much higher and in the order of 20 to $30 \%$.

It is not easy to verify these different predictions empirically. But we have some suggestive evidence from the period since central banks switched to an inflation 
target of 2\%. In the Eurozone countries this happened in 1999 when the European monetary union was started. The ECB then announced an inflation target of $2 \%$. In the US an explicit inflation target of $2 \%$ was only introduced in 2012 by the then Chairman of the Federal Reserve, Bern Bernanke. It is clear, however, that the Federal Reserve pursued an implicit inflation target of close to $2 \%$ from the end of the 1990 s.

In Figure 13 we show the policy rates in the US and the Eurozone since 1999. We observe that these rates were close to zero for a considerable time. In fact the US policy rate was close to zero $45 \%$ of the time, in the Eurozone this was $41 \%$. This is even higher than the prediction of our model. This is probably related to the fact that the recession of 2008-09 was deeper and longer-lasting than normal recessions as it followed a financial crisis (see Reinhart and Rogoff(2009)).

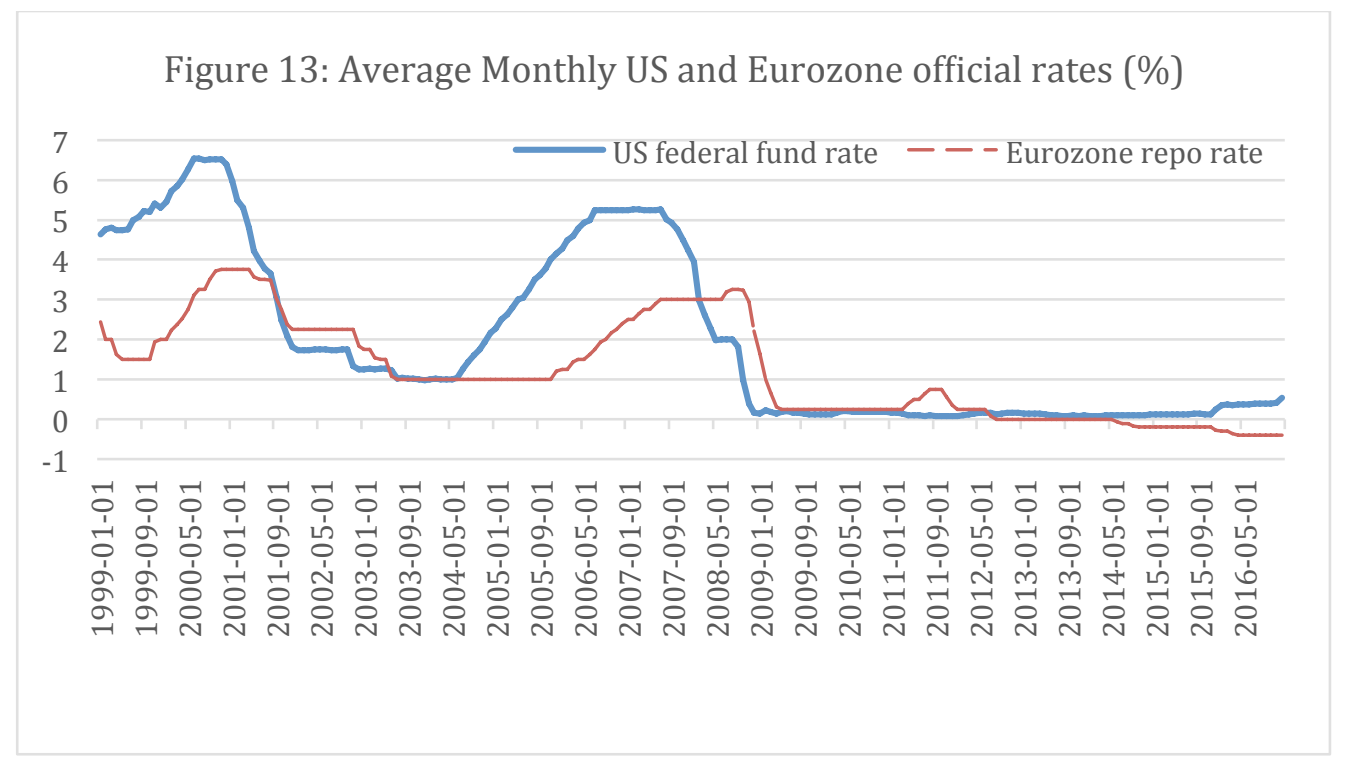

Source: ECB, Statistical Warehouse and Board of Governors of the US Federal Reserve System

In Figure 14, we also show the policy rates of other major central banks since 1999. These are the central banks of Switzerland, Sweden, the UK, Canada, Norway, Australia and New Zealand. In Table 5, we show the probabilities of hitting the ZLB in Canada, Norway, Australia New Zealand, Switzerland and Sweden. We obtained these probabilities by counting the number of months these countries were hitting the ZLB over the total number of months (216). Note that in the case of the UK the interest rate was kept constant at the level of 
0.5\% from 2009 to 2016. The Bank of England seems to have considered 0.5\% to be an effective ZLB.

A factor that leads to the observed difference in the probabilities of hitting the ZLB may be related to the level of the inflation target of a central bank. As shown in Table 5, Switzerland, Sweden and the UK have a relatively low inflation target (about 2\%) while Canada, Norway, Australia and New Zealand have an inflation target which can reach 3\%. This also confirms the prediction of our model, i.e. that countries using a higher inflation target are less likely to hit the ZLB².

Clearly this can only be considered as preliminary evidence. These countries differ among many other dimensions (e.g. the severity of the recession of 2008-9, intensity of banking crisis) that can affect interest rate movements and the probabilities of hitting the ZLB. More empirical analysis is called for.

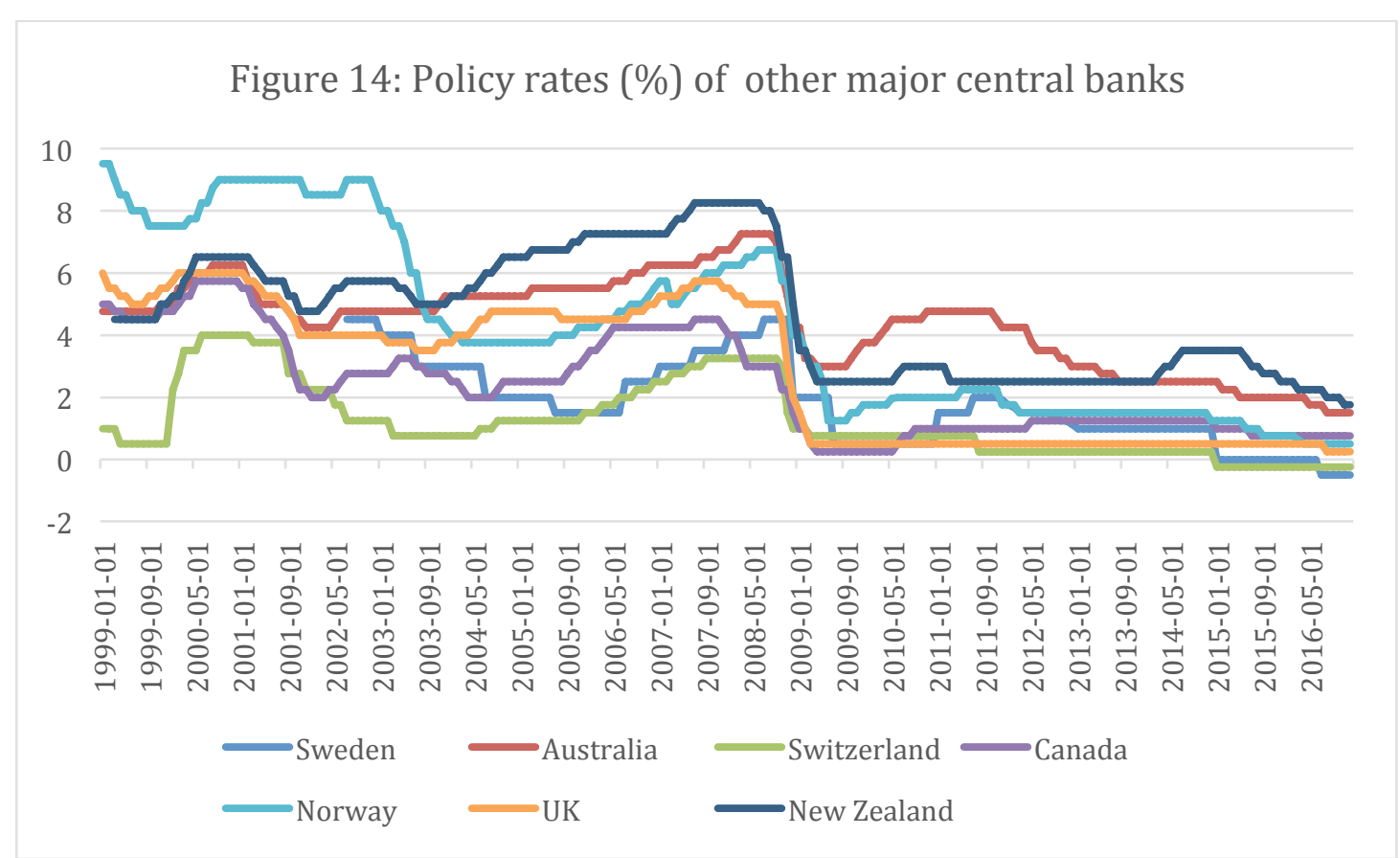

\footnotetext{
${ }^{2}$ Note that Figure 6 (page 22) predicts that countries with an inflation target of $4 \%$ will hit the ZLB $10 \%$ of the time. We find here (table 5) that some countries with an inflation target below $4 \%$ spend $0 \%$ of the time in the ZLB. It should be mentioned here that the results of Figure 6 are based on simulations of 10,000 periods (quarters). During such long periods we find that the interest rates regularly stay away from the ZLB during spells extending to hundred periods.
} 
Table 5. Probability of hitting ZLB and Inflation Target

\begin{tabular}{ccc}
\hline & Inflation target & Probability of Hitting \\
& & ZLB \\
\hline US & $1.7-2 \%$ & $45 \%$ \\
Eurozone & below but close to $2 \%$ & $41 \%$ \\
Switzerland & $<2 \%$ & $30 \%$ \\
Sweden & $2 \%$ & $11 \%$ \\
UK & $2 \%$ & $2 \%$ \\
Canada & $1-3 \%$ & $6 \%$ \\
Norway & $2.50 \%$ & $0 \%$ \\
Australia & $2-3 \%$ & $0 \%$ \\
New Zealand & $1-3 \%$ & $0 \%$ \\
\hline
\end{tabular}

Sources: Inflation target rates are obtained from official websites of the central banks.

The interest rates are obtained from IMF data and the probabilities of hitting ZLB are from authors' own calculation.

\subsection{Forecasting errors}

In this section we compare the mean forecasting errors made by fundamentalists and extrapolators in our model with real-life forecasting errors made by professional forecasters. For the latter we use the Survey of Professional Forecasters (SPF) collected by the ECB. We compare standard measures of forecast errors, i.e. the standard deviation of the forecast errors (STDE), the mean absolute forecast error (MAE) and the root mean squared forecast error (RMSE). We use a study made by the ECB for the Eurozone during the period 1999-2006, and we compare these measures with those obtained in our model. We compute these measures of forecast errors in our model during lengths of 8 years (32 quarters). We repeat this 100 times and take an average. We show the results in table 6. We find that the MAE and RMSE are slightly lower in our model than in the empirical data of the Eurozone. The reverse is true for STDE. Both in our model and in the empirical data the forecast errors relating to output gap (GDP growth) are significantly larger than the forecast errors in inflation. Thus our model mimicks an important feature of real-life forecast errors. 
Table 6: Measures of forecast errors in the behavioral model and in the Eurozone using the SPF

\begin{tabular}{|c|c|c|}
\hline & Behavioral model & Eurozone \\
\hline $\begin{array}{c}\text { Output } \\
\text { MAE }\end{array}$ & 0.81 & 0.9 \\
RMSE & 0.95 & 1.0 \\
STDE & 0.97 & 0.59 \\
Inflation & 0.39 & 0.5 \\
MAE & 0.45 & 0.6 \\
RMSE & 0.47 & 0.38 \\
\hline
\end{tabular}

Source: Eurozone data are from Bowles, et al.(2007). The output forecast errors relate to the growth rate of GDP (not the output gap)

Note: The forecast errors relate to one-year ahead forecasts. I our model this means that we take forecasts four-quarters ahead.

\section{Conclusion}

In this paper we have analyzed the relation between the level of the inflation target and the ZLB constraint imposed on the nominal interest rate. We analyzed this relation in the framework of a behavioral macroeconomic model in which agents experience cognitive limitations, preventing them from forming rational expectations. This forces them to use simple rules of thumb to forecast the output gap and the rate of inflation. Rationality is introduced into the model by allowing agents to learn from their mistakes and to switch to the better performing forecasting rules. The model produces endogenous waves of optimism and pessimism (animal spirits) that, because of their self-fulfilling nature, drive the business cycle and in turn are influenced by the business cycle.

The use of this behavioral model has allowed us to shed new light on the optimal level of the inflation target in a world where a ZLB constraint on the nominal interest rate exists. We found that when the inflation target is too close to zero, the economy can get gripped by "chronic pessimism" that leads to a dominance of negative output gaps and recessions, and in turn feeds back on expectations 
producing long waves of pessimism. The mechanism that produces this chronic pessimism can be described as follows. Endogenous movements in animal spirits regularly produce recessions and negative inflation rates. When that happens, the central bank cannot use its interest rate to boost the economy and to raise inflation as the nominal interest rate cannot become negative. When inflation becomes negative this also implies that the real interest rate increases during the recession, aggravating the latter, and increasing pessimism. The economy can get stuck for a very long time in this cycle of pessimism and negative output gap.

Thus, when the inflation target is set too close to zero the distribution of the output gap is skewed towards the negative territory. The question then is what "too close to zero" means. The simulations of our model, using parameter calibrations that are generally found in the literature, suggests that $2 \%$ is too low, i.e. produces negative skewness in the distribution of the output gap. We find that an inflation target in the range of 3\% to $4 \%$ comes closer to producing a symmetric distribution of the output gap.

We also found that when the economy is pushed into a recession as a result of a negative demand shock, the high inflation target regime has better stabilizing properties. We found that in the high inflation target regime the persistence of the recession is shorter than in the low inflation target regime. That is, when the central bank sets a relatively high inflation target, the capacity of the system to lift itself out of the recession is stronger than when it sets a low inflation target. This is made possible by the stabilizing properties of monetary policies and by the ensuing elimination of self-fulfilling pessimism.

Another major finding of our analysis is that with an inflation target of $2 \%$ (which has become the standard in inflation targeting) the economy hits the ZLB with a probability of $25 \%$ compared to less than $10 \%$ with an inflation target of $4 \%$. These are significantly higher probabilities than those obtained in standard DSGE models. The reason we find significantly higher probabilities has to do with the fact that animal spirits amplify shocks and in combination with the ZLB can keep the economy in a persistent way into negative territory.

The previous results leads to the conclusion that central banks should raise the inflation target from $2 \%$ to a range between 3\% to $4 \%$ (see also Blanchard, et al. 
(2010) and Ball(2014) on this). One might object here that this conclusion does not take into account the potential negative effect on inflation credibility of raising the inflation target to $3 \%$ or $4 \%$. We analyzed this question in the framework of our behavioral model. Our model gives a precise definition of credibility, as the fraction of agents that use the announced inflation target as their rule of thumb to forecast inflation. It turns out that an inflation target of $3 \%$ or $4 \%$ has more credibility than a target of $2 \%$. The reason has to do with what we said earlier. With an inflation target of $2 \%$ the output gap and inflation are more often pushed into negative territory than when the inflation target is $3 \%$ or $4 \%$. Once inflation and output gap are in the negative territory the power of the central bank to affect the output gap and inflation is weakened. As a result, the observed inflation rate will deviate more often from the target, when the target is low, thereby undermining the credibility of the central bank.

One issue that we have not analysed in this paper is how periods of prolonged pessimism that are produced by an inflation target that is set too low affects long term growth. It is not unreasonable to believe that "chronic pessimism" lowers investment in a persistent way thereby lowering long-term growth. As we have not incorporated these long-term growth effects in our model, it is difficult to come to precise conclusions. We leave this issue for further research. 


\section{APPENDIX A: Forecasting rules are AR(1)}

In this appendix we show some results when we impose an $\operatorname{AR}(1)$ structure on the forecasting rules. This does not affect our main results. We show typical simulations in the time domain (using the same parameter values and distribution of the shocks as in the main text). We obtain some more persistence in the business cycles.

Figure A1: Output gap in frequency and time domains (different inflation targets)

$$
\text { Inflation target }=2 \%
$$
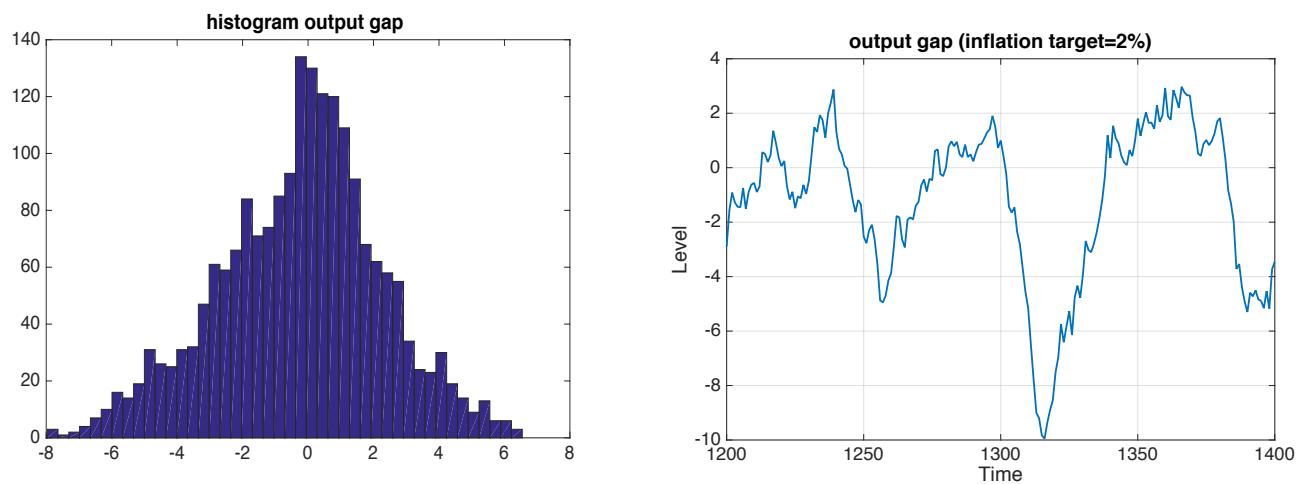

Skewness $=-0.32$

$\mathrm{ZLB}=41 \%$
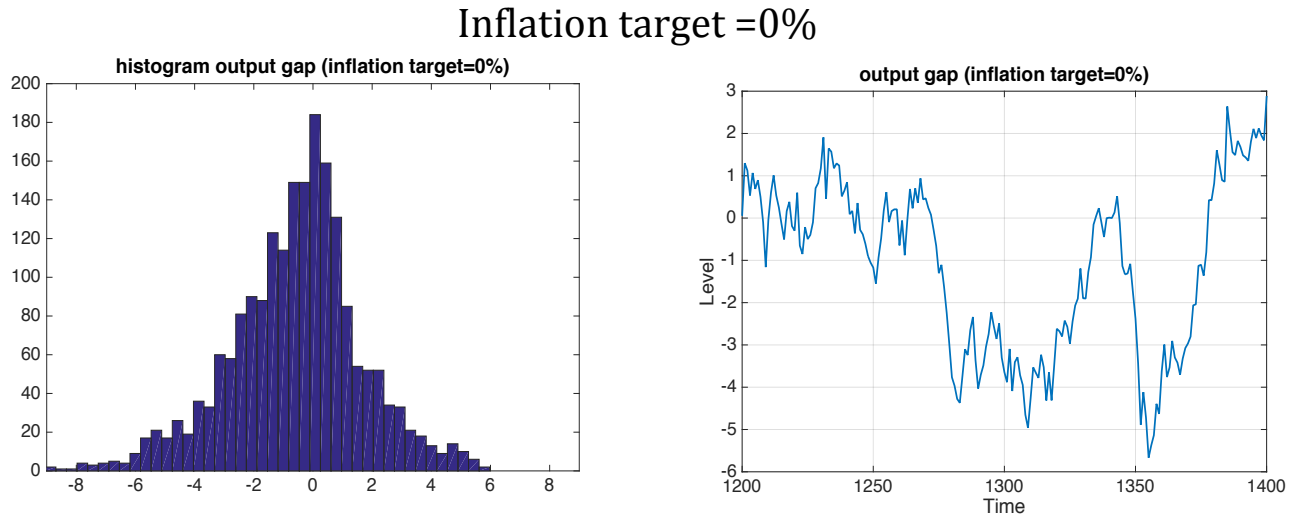

skewness $=-0.72$

$\mathrm{ZLB}=63 \%$ 


\section{APPENDIX B: Relative performance of forecasting rules and their use}

In this appendix we present the relative performance of the extrapolative versus the fundamentalist forecasting rules (Figure A2). This is obtained by taking the difference in the utilities of the extrapolative and the fundamentalist rule. In Figures A3 and A4 we show the fractions of the agents use the extrapolative resp. the fundamentalist rules.

Figure A2

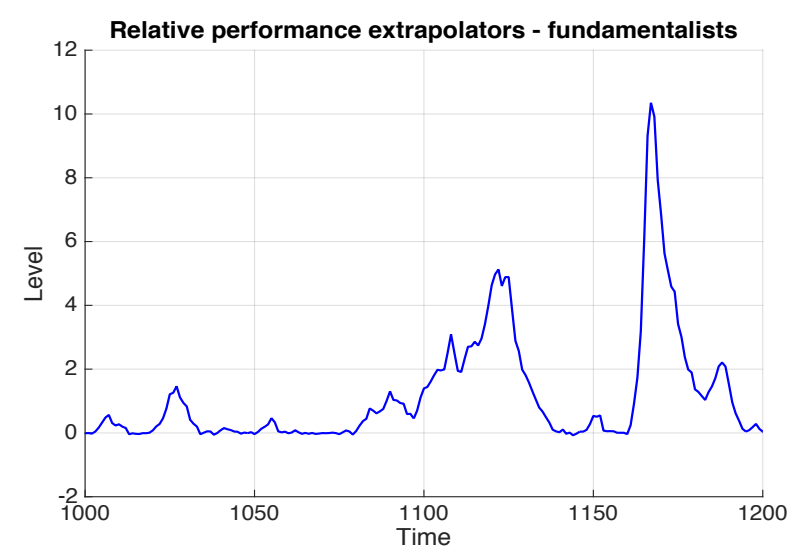

Figure A3

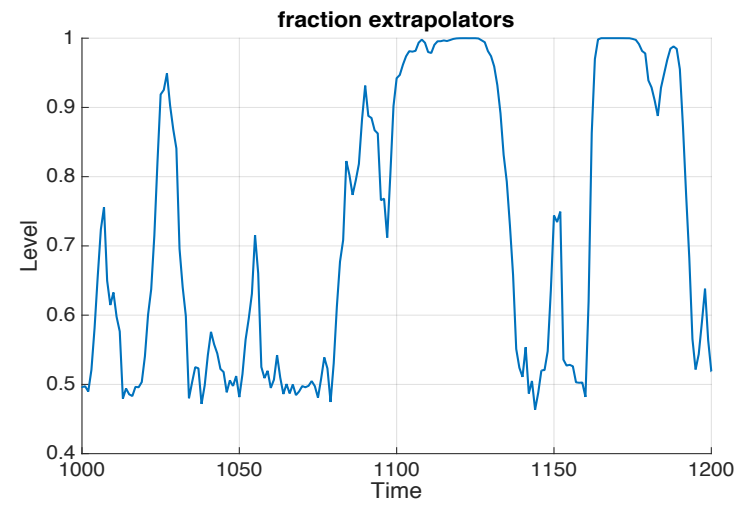

Figure A4

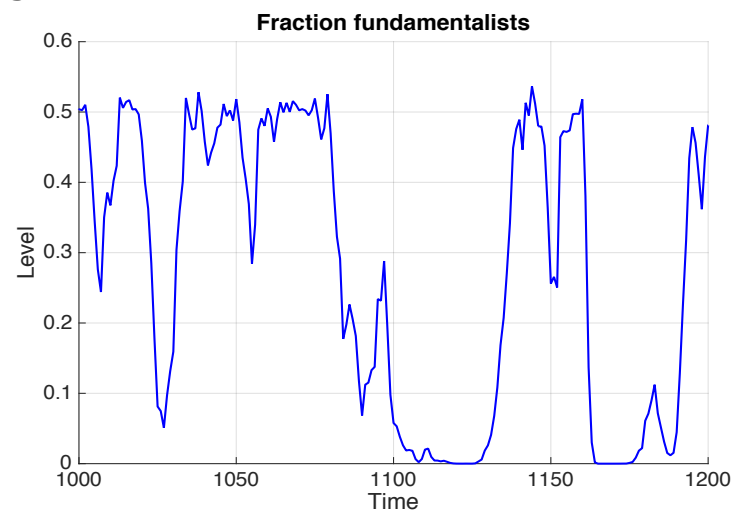

Correlation relative performance and fraction extrapolators $=0.78$ 


\section{APPENDIX C: Choosing the standard deviations of shocks}

In this appendix we describe how we selected the standard deviations in the error terms. We first collected empirical data on the standard deviations of the output gap and inflation in the US and the Eurozone. These are shown in table C1.

Table C1: Standard deviations of output gap and inflation (quarterly observations)

\begin{tabular}{ccccc}
\hline & \multicolumn{3}{c}{ Output gap } & \multicolumn{2}{c}{ Inflation } \\
\hline & U.S. & Eurozone & U.S. & Eurozone \\
Sample period: $2000-2016$ & 1,6 & 1,7 & 1,3 & 1,0 \\
Sample period: $1990-2016$ & 1,7 & -- & 1,3 & -- \\
\hline
\end{tabular}

Source: Author's own calculations using output gap from Oxford Economics and inflation from the US Bureau of Labor Statistics and Eurostat.

We then simulated our model for different standard deviations of the exogenous shocks in inflation (while keeping the standard deviation of output shocks constant) and computed the standard deviations of the simulated output gap and inflation. We did this consecutively for increasing standard deviations of the output shocks. We assumed an inflation target of $2 \%$. The results are shown in Figure C1. This shows the standard deviation of the simulated output gap and inflation for different standard deviations in the inflation shocks (and for a standard deviation of the output gap equal to 0.5 ). We observe that with a standard deviation of the shocks in inflation and of output gap of 0.5 we come very close to the empirically observed standard deviations of the output gap and inflation. It is also interesting to observe that while we assume the same standard deviation in the shocks of output and inflation the model produces a significantly higher standard deviation of the output gap than of inflation. This is also confirmed empirically. Thus, we do not need to assume that the exogenous shocks in the output gap are higher than the shocks in inflation to produce this result. 
Figure $\mathrm{C} 1$ :
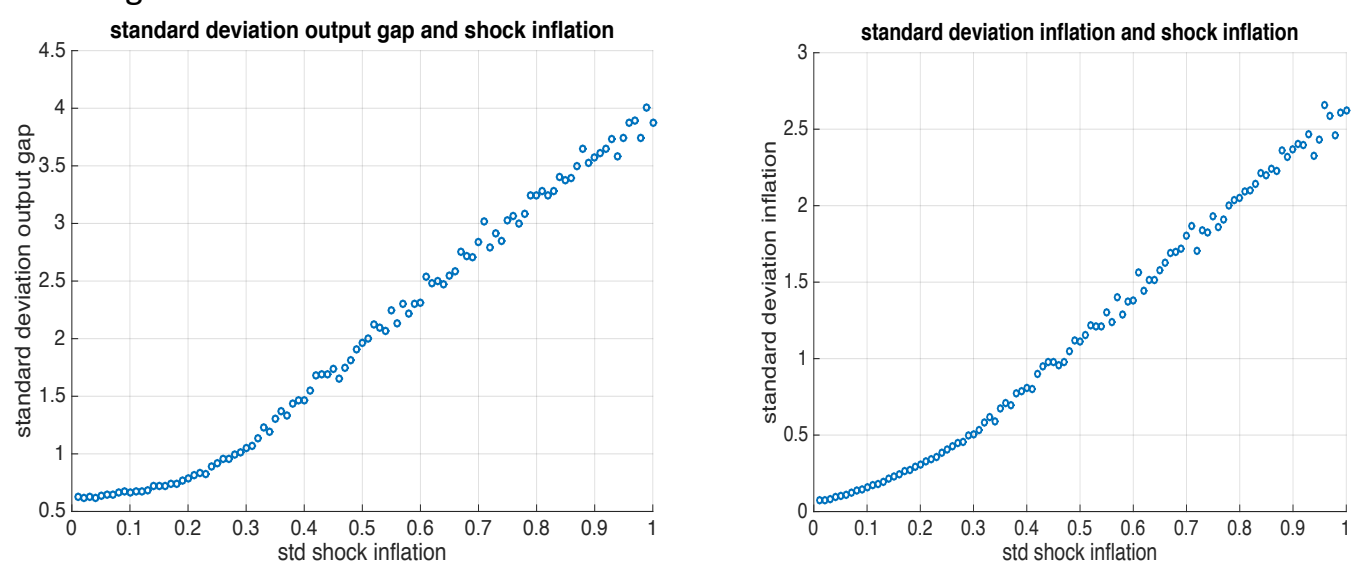

\section{Appendix D: The relation between animal spirits and forecast errors}

In this appendix we show how animal spirits and the forecast errors made by chartists and fundamentalists are related ${ }^{3}$. In order to do so, we make the simplifying assumption that the true dynamics of a particular variable (output gap or inflation) is given by:

$$
y_{t+1}=0.5 y_{t}
$$

Fundamentalists and chartists make forecasts in period $t$ about $y_{t+1}$, i.e. the output gap or inflation that will prevail in $t+1$. The mean forecast error that will be made in period $t+1$ is therefore given by

$$
\bar{e}_{t+1}=\alpha_{f, t} e_{t+1}^{f}+\alpha_{e, t} e_{t+1}^{e}
$$

Note that we multiply the forecast errors made by fundamentalists and chartists in period $t+1$ by the fractions of fundamentalists and chartists in period $t$ since this is the period when these forecasts were made.

If $y_{t}=1>0, y_{t+1}=0.5$

- Fundamentalists' forecast error in $\mathrm{t}+1$ is $e_{t+1}^{f}=0.5-0=0.5$

- Extrapolators' forecast error in $\mathrm{t}+1$ is $e_{t+1}^{e}=0.5-1=-0.5$

As a result the mean forecast error in $t+1$ becomes

\footnotetext{
${ }^{3}$ We are grateful to a referee for proposing this analysis
} 


$$
\bar{e}_{t+1}=\alpha_{f, t} e_{t+1}^{f}+\alpha_{e, t} e_{t+1}^{e}=0.5\left(\alpha_{f, t}-\alpha_{e, t}\right)
$$

This implies that

$$
S_{t}=-2 \bar{e}_{t+1}
$$

In other words animal spirits in period $t$ are correlated with the mean forecast errors in period $t+1$. An alternative way to put this is that the mean forecast errors today are correlated with the animal spirits that prevailed in the previous period.

$$
\bar{e}_{t}=-0.5 S_{t-1}
$$

A similar argument can be developed when $y_{t}=-1>0$, so that $y_{t+1}=-0.5$

In that case we find

$$
\bar{e}_{t+1}=\alpha_{f, t} e_{t+1}^{f}+\alpha_{e, t} e_{t+1}^{e}=-0.5\left(\alpha_{f, t}-\alpha_{e, t}\right)
$$

so that

$$
S_{t}=-2 \bar{e}_{t+1}
$$

Simulating the model over 10,000 periods we find a correlation between $S_{t}$ and $\bar{e}_{t+1}$ of -0.23 


\section{References}

Akerlof, G., and Shiller, R., (2009), Animal Spirits. How Human Psychology Drives the Economy and Why It Matters for Global Capitalism, Princeton University Press, 230pp.

Anderson, S., de Palma, A., Thisse, J.-F., 1992, Discrete Choice Theory of Product Differentiation, MIT Press, Cambridge, Mass.

Aruoba, S. B., \& Schorfheide, F. (2013). Macroeconomic dynamics near the ZLB: A tale of two equilibria. papers.ssrn.com

Ascari, G., Fagiolo, G., and Roventini, A. (2015). Fat-Tail Distributions And Business-Cycle Models. Macroeconomic Dynamics , 19(02):465-476.

Ball, L., (2014), The Case for a Long-Run Inflation Target of Four Percent, IMF Working Paper, 14/92, International Monetary Fund, Washington, D.C.

Blanchard, O., Dell'Ariccia, G., Mauro, P., (2010), Rethinking Macroeconomic Policy, IMF Staff Position Note, February 12, International Monetary Fund, Washington, D.C.

Blattner, T., and Margaritov, (2010), Towards a Robust Policy Rule for the Euro Area, ECB Working Paper Series, no. 1210, July.

Bowles, C., Friz, R., Genre, V., Kenny, G., Meyler, A., and Rautanen, T., (2007), The ECB Survey of Professional Forecasters (SPF), A Review after Eight Years' Experience, ECB Occasional Paper Series, April.

Branch, W., and Evans, G., (2006), Intrinsic heterogeneity in expectation formation, Journal of Economic theory, 127, 264-95.

Branch, W., and Evans, G., (2014), Unstable Inflation Targets, unpublished, University of California, Irvine.

Brazier, A., Harrison, R., King, M., Yates, T., (2008), The danger of inflation expectations on macroeconomic stability: heuristic switching in an overlapping generations monetary model, in International Journal of Central Banking, 32:2428-2452.

Brock, W., and Hommes, C., (1997), A Rational Route to Randomness, Econometrica, 65, 1059-1095

Calvo, G., (1983), Staggered prices in a utility maximizing framework. Journal of Monetetary Econ.onomics12, 383-398.

Chung, H., Laforte, J. P., Reifschneider, D., \& Williams, J. C. (2012). Have we underestimated the likelihood and severity of zero lower bound events? Journal of Money, Credit and Banking, 44(s1), 47-82.

Coenen, Günter. (2003) "Zero Lower Bound: Is It a Problem in the Euro Area?" ECB Working Paper No. 269

Colander, David, Peter Howitt, Alan Kirman, Axel Leijonhufvud and Perry Mehrling. 2008. "Beyond DSGE Models: Toward an Empirically Based Macroeconomics." American Economic Review, 98(2): 236-40. 
De Grauwe, P., and Grimaldi, M., (2006), The Exchange Rate in a Behavioural Finance Framework, Princeton University Press.

De Grauwe, P., (2012), Lectures on Behavioral Macroeconomics, Princeton University Press.

De Grauwe, P., and Ji, Y., (2016), International Correlation of Business Cycles in a Behavioral Macroeconomic Model, CEPR, Discussion Paper, April.

Delli Gatti, D., Di Guilmi, C;, Gaffeo, E., Giuloni, G., Gallegati, M., Palestrini, A., (2005), A new approach to business fluctuations: heterogenous interacting agents, scaling laws and financial fragility, Journal of Economic Behavior and Organization, vol. 56, 489-512

Eggertsson, G. B., \& Krugman, P. (2012). Debt, deleveraging, and the liquidity trap: A fisher-minsky-koo approach, Quarterly Journal of Economics, 127(3), 1469-1513.

Eggertsson, Gauti B., and Michael Woodford. (2003) "The Zero Bound on Interest Rates and Optimal Monetary Policy. Brookings Papers on Economic Activity, 2, 139-211.

Evans, G., and Honkapohja, S., 2001, Learning and Expectations in Macroeconomics, Princeton University Press, 421pp.

Fagiolo, G., Napoletano, M., Roventini, A., (2008), Are Output Growth Rate Distributions Fat-Tailed: Evidence for OECD-countries, Journal of Applied Econometrics, 23: 639-669

Fagiolo, G., Napoletano, M, Piazza, M., Roventini, A., (2009), Detrending and the Distributional Properties of U.S. Output Time Series, Economics Bulletin, 29:4.

Farmer, Roger, E.A., (2006), Animal Spirits, Palgrave Dictionary of Economics.

Farmer, J. Doyne, and Duncan Foley. 'The Economy Needs Agent- Based Modelling.' Nature 460 (2009): 685-686

Fernandez-Villaverde, J. and Rubio-Ramirez, J. F. (2007). Estimating

Macroeconomic Models: A Likelihood Approach. Review of Economic Studies, 74(4):1059-1087.

Fisher, I. (1933). The debt-deflation theory of great depressions. Econometrica: Journal of the Econometric Society, 337-357.

Gabaix, X., (2014), A Sparsity-Based Model of Bounded Rationality, The Quarterly Journal of Economics (2014), 1661-1710.

Galí, J., (2008), Monetary Policy, Inflation and the Business Cycle, Princeton University Press, 203pp.

Gigerenzer, G., and P.M. Todd, (1999), Simple Heuristics That Make Us Smart. New York: Oxford University Press.

Hommes, C., (2016), Behavioral Macroeconomics with Heterogeneous Expectations and Interacting Agents, Discussion Paper, CenDEF, University of Amsterdam. 
Hommes, C., and Lustenhouwer, J., (2016), Managing Heterogeneous and Unanchored Expectations: A Monetary Policy Analysis, Working Paper, Tinbergen Institute, Rotterdam.

Justiniano, A. and Primiceri, G. E. (2008). The Time-Varying Volatility of Macroeconomic Fluctuations. American Economic Review , 98(3):604641.

Kahneman, D., 2002, Maps of Bounded Rationality: A Perspective on Intuitive Judgment and Choice, Nobel Prize Lecture, December 8, Stockholm (also published in American Economic Review, 2003).

Kirman. A., (1992), Whom or What Does the. Representative Individual Represent?, Journal of Economic Perspectives • vol. 6, no. 2, Spring, pp . 117-136.

Kirman, A., (1993), Ants, Rationality and Recruitment, Quarterly Journal of Economics, 108: 137-156.

Koo, R. C. (2011). The Holy Grail of Macroeconomics: Lessons from Japan's Great Recession. John Wiley \& Sons.

Reifschneider, D., and Williams, J., (1999), Three Lessons for Monetary Policy in a Low Inflation Era, Board of Governors of the Federal Reserve, Washington, D.C.

Reinhart, C. and Rogoff, K., (2009), This Time is Different. Eight Centuries of Financial Folly, Princeton University Press, Princeton, NJ.

Schmitt-Grohe, Stephanie, and Martin Uribe. (2007) “Optimal Inflation Stabilization in a Medium-Scale Macroeconomic Model." In Monetary Policy Under Inflation Targeting, edited by Klaus Schmidt-Hebbel and Rick Mishkin, pp. 125-86. Santiago, Chile : Central Bank of Chile.

Smets, F. and Wouters, R., (2003), An Estimated Dynamic Stochastic General Equilibrium Model, Journal of the European Economic Association, 1, 11231175.

Sonnenschein, H. (1972). "Market excess-demand functions". Econometrica. 40 (3): 549-563.

Tesfatsion, L., and KL Judd, (2006), Handbook of Computational Economics Volume 2: Agent-Based Computational Economics, Elsevier.

Westerhoff, F., and Franke, R., (2012), Agent-based models for economic policy design: two illustrative examples. Working Paper No. 88, Iowa State University.

Woodford, M., (2003), Interest and Prices: Foundations of a Theory of Monetary Policy, Princeton University Press.

\footnotetext{
${ }^{1}$ It is now standard in DSGE-models to use a pricing equation in which marginal costs enter on the right hand side. Such an equation is derived from profit ${ }^{2}$ In De Grauwe(2012) more complex rules are used, e.g. it is assumed that agents do not know the steady state output gap with certainty and only have biased
} 
estimates of it. This is also the approach taken by Hommes and Lustenhouwer(2016).

${ }^{3}$ Note that according to (4) fundamentalists expect a deviation of the output gap from the equilibrium to be corrected in one period. We have experimented with lagged adjustments using an AR(1) process. These do not affect the results in a fundamental sense. We show and discuss the results in Appendix.

${ }^{4}$ There are some attempts to provide micro-foundations of models with agents experiencing cognitive limitations, though. See e.g. Kirman, (1992), Delli Gatti, et al.(2005). A recent attempt is provided by Gabaix(2014). See also Hommes and Lustenhouwer(2015) who derive microfoundations of a model similar to the one used here, but assuming quite strong cognitive capacities of agents. We have not pursued this here.

${ }^{5}$ We do not show impulse responses to positive demand shocks. The reason is that when positive shocks occur the central bank, that wishes to raise the interest rate, is not constrained by the ZLB. As a result, impulse responses are very similar for different levels of the inflation targets.

${ }^{6}$ We show only the impulse responses of positive supply shocks, because only under this shock does the ZLB constraint become effective. 